Florida International University

FIU Digital Commons

FIU Electronic Theses and Dissertations

University Graduate School

3-31-1999

\title{
A study of the differences among African American, Hispanic and Anglo women on the perceived barriers and strategies to career advancement in public school administration
}

Marie Byrd

Florida International University

DOI: $10.25148 /$ etd.FI14052510

Follow this and additional works at: https://digitalcommons.fiu.edu/etd

Part of the Educational Administration and Supervision Commons

\section{Recommended Citation}

Byrd, Marie, "A study of the differences among African American, Hispanic and Anglo women on the perceived barriers and strategies to career advancement in public school administration" (1999). FIU Electronic Theses and Dissertations. 2004.

https://digitalcommons.fiu.edu/etd/2004

This work is brought to you for free and open access by the University Graduate School at FIU Digital Commons. It has been accepted for inclusion in FIU Electronic Theses and Dissertations by an authorized administrator of FIU Digital Commons. For more information, please contact dcc@fiu.edu. 
FLORIDA INTERNATIONAL UNIVERSITY

Mliami, Florida

\begin{abstract}
A STUDY OF THE DIFFERENCES AMONG AFRICAN AMERICAN. HISPANIC, AND ANGLO WOMEN ON THE PERCEIVED BARRIERS AND STRATEGIES TO CAREER ADVANCEMENT TI PUBLIC SCHOOL ADMINISTRATION
\end{abstract}

A dissertation submitted in partiai fulfillment of the requirements for the degree of

DOCTOR OF EDUCATION

in

EDUCATIONAL ADMINISTRATION AND SUPERVISION

by

Marie Byrd

1999 
To: $\quad$ Dean Robert Vos

College of Education

This dissertation, written by Marie Byrd, and entitled A Study of the Differences Among African American, Hispanic, and Angle Women on the Perceived Barriers and Strategies to Career Advancement in Public School Administration, having been approved in respect to style and intellectual content, is referred to you for judgment.

We have read this dissertation and recommend that it be approved.

Kingsley Banya

Pauletic Johnson

Sarah W.Y. Pell, Major Proressor

Date of Defense: March 31, 1999

The dissertation of Marie Byrd is approved.

Dean Robert Vos

College of Education

Dean Ríchard L. Campbell Division of Graduate Studies

Florida International University, 1999 
(C) Copyright 1999 by Marie Byrd

All rights reserved. 


\section{DEDICATION}

I dedicate this dissertation to my family: Mama, Joe, William, Shirley.

Henry, Roy, Johnny, Liz, Pos, Albert, and Donald. Thank you for giving me the foundation I needed to persevere through four years of doctoral studies and for your assurances that you are proud of me regardless of my educational accomplishments. 


\section{ACKNOWLEDGMENTS}

I wish to thank Dr. Sarah Pell, my advisor and major professor, who has been the source of encouragement and motivation. Only through Dr. Pell's influence and invaluable guidance was I able to complete this project. Thank you also to Dr. Paulette Johnson, my statistics professor and committee member, whose expert tutelage assisted me through the tediousness of the later chapters. Her patience was invaluable. I also wish to acknowledge committee member, Dr. Kinglsey Banya for his involvement. Thank you to Dr. Peter Cistone who guided me through the earlier stages of my doctoral studies.

Gratitude is also extended to my former doctoral classmate and study partner Dr. Steve Gallon III. Thank you for demonstrating the process of setting goals and achieving them. Thanks also to former doctoral classmates Dr. Channey Johnson and Dr. David Gupta for their untimely advice and encouragement. I also wish to thank Debra Bell and Kevin Seymour for believing in me for the past 13 years and for providing the reassurance that my goal will be achieved. Special thanks must be given to Mrs. Urban and Mrs. Thompson from North County Elementary for their support and to Chance for printing all those mailing labels.

Finally. my deepest gratitude is extended to the female administrators who took the time out of their hectic schedules to respond to the questionnaire. Without their honesty and candidness, this study would not have been possible. 


\section{ABSTRACT OF THE DISSERTATION}

A STUDY OF THE DIFFERENCES AMONG AFRICAN AMERICAN, HISPANIC, AND ANGLO WOMEN ON THE PERCEIVED BARRIERS AND STRATEGIES TO CAREER ADVANCEMENT IN PUBLIC SCHOOL ADMINISTRATION

by

Marie Byrd

Florida International University, 1999

Miami, Florida

Professor Sarah W. J. Pell, Major Professor

Women have been traditionally excluded from the ranks of principals and district administrators in public school systems throughout the country. Traditionally, Anglo women have been more successful than African American and Hispanic women in breaking down the barriers that impede their ascension to the top. The purpose of this study was to ascertain how African American, Hispanic, and Anglo higher-level female administrators perceive the barriers that hinder their progress, the effects of the barriers, and the strategies to overcome the barriers. 
Two hundred, sixty female administrators employed with Miami-Dade County Public Schools and serving in the role of principal or higher were mailed a questionnaire consisting of 49 questions centering on personal and professional characteristics, perceptions of barriers, perceived effects of barriers, and strategies to overcome the barriers. One hundred, seventy-five questionnaires were returned. To analyze the respondents' personal and professional characteristics, cross tabulations were conducted on the demographic information and on the strategies. A $\mathrm{OVVA}$ was conducted on the barriers and the effects of the barriers by ethnic groups. Tukey's test for post-hoc comparisons was utilized to identify groups with means significantly divergent from those of other ethnicities.

The data revealed that Hispanic female higher-level administrators who returned the questionnaire were more likely to be manied and have children as compared to Anglo and African American female administrators. When addressing the barriers to career success, African American females had a higher mean score on 14 of the 17 barriers to career success as compared to the other ethnic groups. Hispanic female administrators proved to be more successful in utilizing the strategies to overcome career barriers. The strategy, forming a "New Girl Network," was the least utilized with 79 of the respondents reporting that they had never used it. 
It is concluded that there is strong need for female administrators to network, mentor, and support one another. Also, it is imperative that the success of particular groups in certain areas is shared with others. 
CHAPTER

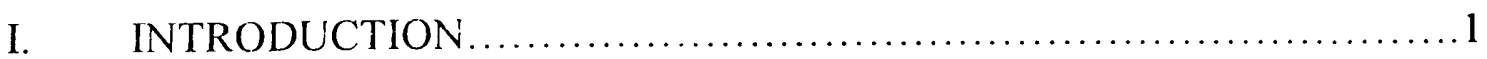

Background............................................

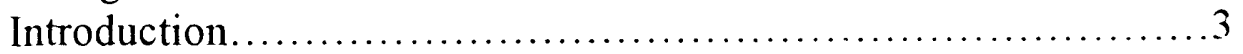

Objectives of the Siudy................................... 4

Statement of Hypotheses.................................... 5

Significance of the Study ...................................... 5

Research Design and Methodology ...........................8

Delimitations of the Study................................... 9

Definition of Terms......................................... 10

Organization of the Study.................................11

II. LITERATURE REVIEW ....................................... 12

The History of Women in Educational Leadership.............. 12

The Status of Women in Public Schools Today.................. 16

Minority Women in Educational Administration................25

African American Women and Educational Administration... .. . 28

Hispanic Women and Educational Administration...............31

Barriers to Career Advancement............................35

Strategies Utilized to Overcome Barriers......................40

Conclusions............................................46

III. RESEARCH DESIGN AND METHODOLOGY......................49

Overview.................................................... 49

Target Population..................................... .50

Instrumentation........................................... 51

Format of the Questionnaire $\ldots \ldots \ldots \ldots \ldots \ldots \ldots \ldots \ldots \ldots \ldots . . \ldots 2$

Data Collection Method....................................53

Data Analysis.........................................54

IV. PRESENTATION OF R.ATA .................................... 56

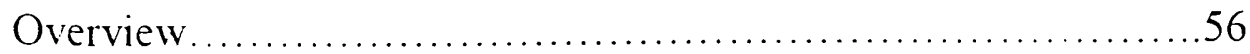

Reliability Analysis.....................................58 
Personal and Professional Characteristics of Administrators. 59

Personal Factors

Ethnic Distribution of Administrators....................60

Number of Years Teaching............................61

Age Distribution of Administrators......................62

Marital Status of Administrators...........................63

Administrators With Children Living at Home.............65

Place of Birth of Administrators..........................66

Highest Educational Degree of Administrators.............67

Age of Job Appointment of Administrators................68

Professional Characteristics.....................................69

Goal Orientation and Perceptions of Success...............69

Perception of Barriers to Career Advancement Which Showed

Significance by Ethnicity.................................. 71

Perception of Barriers to Career Advancement Which Did Not

Show Significance by Ethnicity..............................74

Ranks of Means of Perceived Barriers to Career Advancement.... 76

Perceptions of the Effects of the Barriers on Career Advancement.81

Successful Strategies to Career Advancement..................86

Voluntary Narrative Section................................96

V. SUMMARY, DISCUSSION, CONCLUSIONS, AND

RECOMMENDATIONS .................................. 107

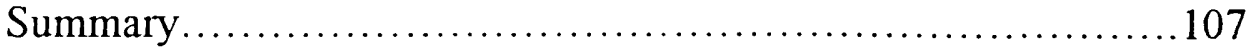

Discussion of Findings.................................... 109

Conclusions............................................ 119

Recommendations for Strategies of Change.................... 122

Recommendations for Future Research.....................125.

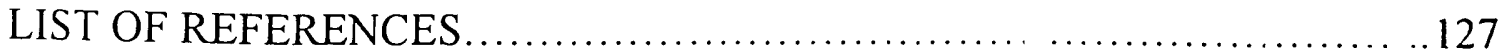

APPENDICES .................................................... 135

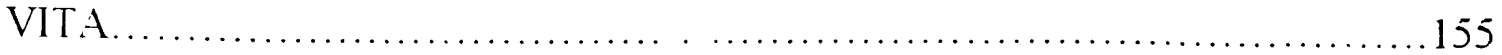




\section{LIST OF TABLES}

TABLE

PAGE

1 Job Titles of Females With Higher-Level Administrative Positions by Ethnicity ..............................................62

2 Age and Marital Status of Females With Higher-Level Administrative Positions by Ethnicity.

3 Number of Children of Females With Higher-Level Administrative Positions by Ethnicity.

4 Highest Degree of Females With Higher-Level Administrative Positions by Ethnicity .... .68

5 Personal Characteristics of Females With Higher-Level Administrative Positions by Ethnicity

6 Significant Differences for Barriers Perceived by Ethnicity....

7 Marginally Significant Differences for Barriers Perceived by Ethnicity... 75

8 Rank of Means With Standard Deviations for the Perceived Barriers to Career Advancement of Black/Non Hispanic Higher-Level Female Administrators Ranked From Serious Factor to Not a Factor. .78

9 Rank of Means With Standard Deviations for the Perceived Barriers to Career Advancement of White/Non Hispanic Higher-Level Female Administrators Ranked from Serious Factor to Not a Factor.

10 Rank of Means With Standard Deviations for the Perceived Barriers to. Career Advancement of Hispanic Higher-Level Feniale Administrators Ranked from Serious Factor to Not a Factor

11 Significant Differences for the Perceived Effects of Barriers by Ethnicity....

12 Non-Significant Differences for the Perceived Effects of Barriers by Ethnicity.... 
13 Significant Tests of Percentages of Success for Strategies by Ethnicity....88

14 Significant Tests by Ethnicity of Percentages of Success for Strategies....91

15 Marginally Significant Tests of Percentages of Success for Strategies by Ethnicity.

16 Non-Significant Tests of Percentages of Success for Strategies by Ethnicity

17 Tests of Non-Significant Percentages of Success for Strategies by Ethnicity....

18 Voluntary Narrative Responses on the Subject of the Difficulties of Females in Advancement as it Relates to Males/Sexism

19 Voluntary Narrative Responses of Respondents on the Subject of Discrimination in Advancement as it Relates to Males/Sexism

20 Voluntary Narrative Responses of Respondents on the Subject of Females Assisting Other Females in the Advancement Process

21 Voluntary Narrative Responses of Respondents on the Subject of Racial/Ethnic Barriers Facing Female Administrators.

22 Voluntary Narrative Responses of Respondents on the Subject of Other Barriers Encountered by Female Administrators

23 Voluntary Narrative Responses of Respondents Regarding Other Barriers Met by Female Administrators. 104

24 Voluntary Narrative Responses of Respondents Who Do Not Experience Barriers.................................................... 105 


\section{Chapter One - Statement of the Problem}

\section{Background}

If the challenges of the $21^{\text {st }}$ century are to be met successfully, education must transform its orientation from one of exclusion to inclusion (Brown \& Irby, 1995). Women are included in the many positions of instruction throughout the public school system, but excluded from the ranks of principals and district administrators. The field of public school administration is dominated almost exclusively by men (Funk, 1986). Morie and Wilson (1996) found that women outnumber men in school administration graduate programs and in the teaching ranks of American public schools. However, women continue to be underrepresented in upper administrative positions. For many years, national trends have shown that white males hold the majority of public school administrative positions (Patterson, 1994). What are the perceived barriers that prevent women from aspiring and obtaining higher level administrative positions? Is it a process of socialization, institutional discrimination, a lack of motivation, limited professional preparation, a lack of mentors, a decline in the job market, or an unforeseen or unrevealed barrier? After decades of civil rights legislation and women's movement activities, a selected group of society is still absent from the higher ranks of school administration. 
Anglo women have been more successful than African American women and Hispanic women in breaking down the barriers that impede their ascension to the top (Gill \& Showell, 1991). Hawkins (1993) stated that, "Nobody takes care of the African American female, we take care of ourselves. It's not fair, but that's the way it's been for hundreds of years." During the 1960's, after the Supreme Court's historic desegregation ruling in 1954, the number of African American principals in the 11 southern border states (Virginia, North Carolina, South Carolina, Florida, Kentucky, Tennessee, Georgia, Alabama, Mississippi, Louisiana, and Arkansas) actually dropped over 95 percent (Coursen, 1989). The legal system of segregation was replaced by urban residential segregation that relegated African American administrators to mostly African American schools. Of those African American administrators, very few were female.

In the past, little research has been conducted on Hispanic female administrators and their perceived barriers to higher level administrative positions. Data collected from Hispanic women show that their placement as administrators is largely relegated to Hispanic elementary schools (Ortiz, 1982). Many state that only Hispanic administrators can solve the problems at Hispanic schools (Padilla, 1995; Reyes \& Valencia, 1995). Very few Hispanic women attain the position as a secondary principal (Carr, 1995). Gorena (1996) found that traditional Hispanic cultural values and ethnicity were seen as a hindrance to their career advancement. 
It is of interest to all administrators and educators as to how African American women, Hispanic women, and Anglo women perceive the barriers that impede their progress. Is the success of the Anglo woman, compared to that of the African American and Hispanic woman, attributed to a difference in the perception of the barriers that are faced and the strategies utilized to overcome those barriers?

Introduction

Since the turn of the century, women have been predominant as professionals in the public schools as teachers. Yet, women have never been held equal to men in the management of schools. Educational institutions have been deprived of the leadership skills, management styles, and competence of the people who have historically dominated their instructional ranks. In addition, the future leaders of this society, the children, are faced daily with gender-based role models that could have a major influence on their career aspirations. This could lead to a perpetuation of the cycle which entails girls choosing only those careers that have been traditionally deemed as feminine in nature (i.e., nurses, teachers).

The current inequality in the representation of females in higher administrative positions has been a product of historical and societal pattenis in the field of education. These patterns have determined the constraints women have 
faced and continue to face when they attempt to enter school administration (Ginn, 1989). The limited success by Anglo women must be examined and compared to that of African American and Hispanic women to determine the approaches all women should acquire in their endeavors to become higher level administrators in the public school system. These findings will lead to the development of a comprehensive program for the promotion of greater gender equity for African American, Hispanic, and Anglo women.

\section{Objectives of the Study}

The objectives of the study are as follows:

1) To examine any distinctions between African American, Hispanic, and Anglo female public school administrators with respect to thie batriers they perceive as hindering their climb up the ladder.

2) To analyze the perceived effects of the barriers utilized by African American, Hispanic, and Anglo women in overcoming the obstacles seen as hindering their ascension in the public school system. 
3) To explore the strategies utilized by Anglo, Hispanic, and African American women in overcoming the barriers they perceive as hindering their climb up the ladder.

\section{Hypotheses}

The hypotheses for this study are:

1) There is a significant difference among African American, Hispanic, and Anglo women on the barriers perceived as hindering their career advancement in their aspirations to become higher-level public school administrators.

2) There is a significant difference among African American, Hispanic, and Anglo women on the perceived effects of the barriers seen as hindering their career advancement in their aspirations to become higher-level public school administrators.

3) There is a significant difference among African American, Hispanic, and Anglo women on the strategies utilized to overcome the barriers perceived as hindering their career advancement in their aspirations to become higher-level public school administrators. 


\section{Significance of the Study}

Throughout history, women have been virtually ignored as potential leaders in many professions (Betz \& Fitzgerald, 1987; Campbell, 1984; Morrison \& Glinow, 1990). Their initial encounters with difficulties usually occur at the entry level due to the dominance of men at the initial stages of employment. In public education, however, a unique practice has existed. Women have represented the majority of the pool from which the leaders were chosen, but their presence vanishes in the upper levels of the hierarchy. Patterson (1994) attributes this to: 1) the assumption that leadership as defined by white males is superior; 2) the tendency of those in power to avoid cultural conflict; 3) the historically based separation of management functions from teaching; 4) the adherence to a bureaucratic school structure; and 5) socialization processes that limit women from aspiring to leadership positions.

An abundance of research has been conducted as to why in public education, where women are the majority, the minority group of men have dominated the leadership ranks (Lesser, 1978; Marsha11, 1981; Schmuck, 1977; Stockard \& Kempner, 1981). This has led to men receiving preference in the appointment to the top positions. The aforementioned past stidies on the inequalities of the hiring of public school administrators have focused on the documentation of the existence of barriers for women, strategies to overcome the 
barriers, and the effect of the barriers on the women. This study concentrates on a different perspective of the dilemma. It categorizes the women into racial groups: African American, Hispanic, and Anglo. The personal and professional characteristics of African American, Hispanic, and Anglo women have been analyzed to ascertain any similarities or differences. Also, the perceptions that these three racial groups have toward the barriers is examined and analyzed including the strategies they have utilized to overcome these obstacles. This information is significant because it has been shown that Anglo women have had limited success since the affirmative action programs were instituted in the 1970's. Ginn (1989) summarized the common objectives of these programs as: 1) to increase the population of women administrators; 2) to heighten awareness among school boards and superintendents; 3) to develop women-oriented graduate training models; 4) to help locate jobs for participants; and 5) to enlighten prospective female administrators in organizational behavior, sex roles and socialization, and personal roles and styles. The implementation of these programs has somewhat improved the plight of women in their advancement in the arena of public school administration. Mirority women, Hispanic and African American, have had continued difficulties despite the focus and research.

The difficulties that African American women have lad in public school administration have been well documented. Gill and Showell (1991) state that 
African American women may enjoy holding lower level traditional administrative positions, but opportunities for reaching the top were narrow and may not exist in many instances. Coursen (1989) felt that although women's representation in administration, especially the principalship, has improved, African American representation has increased only slightly. Among the many roadblocks that these women have had to face include finding a mentor (Allen, 1995). Ortiz (1982) and Gorena (1996) reported similar findings on studies of Hispanic females. In fact, Ortiz (1982) found that Hispanic women were given jobs only as teachers of Hispanic students, administrators of special projects, principals of problem Hispanic elementary schools, and only a few secondary principalships.

Female administrators of all races and ethnic groups must circumvent or overcome the obstructions to their rise up the hierarchy. In order to achieve this end, it is imperative that the reasons for the success of some are shared with others.

\section{$\underline{\text { Research Design and Methodology }}$}

Female administrators in Miami-Dade County Public Schonls were chosen as the target population due to the diverse population represented in the administrative ranks. Female administrators employed with Miami-Dade County 
Public Schools and serving in the role of principal or higher were mailed the Survey of the Perceived Barriers and Strategies to Career Advancement for

Women. Those results were examined utilizing several statistical techniques to obtain and analyze data for the investigation of the differences among African American, Hispanic, and Anglo women on the perceived barriers during their ascension up the career ladder and the strategies utilized to overcome those barriers. The major statistical procedures that were utilized in this study include basic descriptive statistics and cross tabulations by the three racial groups on the demographic information provided and on the strategies utilized to overcome the barricrs. One-way Analyses of Variance by ethnicity was conducted on each of the perceived barriers to career advancement and on the effects of the perceived barriers. For significant differences, post hoc (Tukey's) comparisons were conducted. Also, three reliability coefficients (Cronbach's Alpha) were determined for the perceived barriers, the effects of the perceived barriers, and the strategies utilized to overcome those barriers.

\section{Delimitations of the Study}

The population was comprised of female administrators in an urban school district in the southeastern United States. Participation was limited to those with 
the status of principal, director, associate superintendent, assistant superintendent, deputy superintendent, or region superintendent.

This study did not include any male administrators or female administrators with the status of assistant principal. Since the district superintendent was a male, he was not be included.

The participants completed a survey. Therefore, it was assumed that all participants were be equally forthcoming in their responses.

\section{Definition of Terms}

The following terms used in the study are defined:

African American - Black/Non Hispanic; any person of African ancestry who resides in the United States (including natives of Bahamas, Jamaica, Haiti, and other Caribbean Islands)

Hispanic - $\quad$ any Spanish speaking person of Latin origin whom lives in the United States.

Anglo - $\quad$ White/Non Hispanic; a White citizen of the United States of European descent

Barriers - $\quad$ anything that hinders progress

Hisher Level Administrators - those administrators with the status of principal or higher 

this paygrade.

\section{Organization of the Study}

The remaining chapters of this study are organized as follows: Chapter 2 contains a review of related research on the historical perspective of women in educational administration, the current status of women in educational administration, the barriers faced by African American, Hispanic, and Anglo women to career advancement and the strategies they have utilized for change; Chapter 3 contains a detailed description of the research methodologies utilized in this study; Chapter 4 includes the presentation of the findings and the interpretation of the results of the study; Chapter 5 presents the discussion of the findings, the implications, and the conclusions and recommendations for further research. 


\section{Chanter Two-Review of Literature}

The studies highlighted in this literature review examine the dominant theoretical frameworks that guide research on women in administration and discuss various studies focusing on the barriers that deter the ascension of women in educational administrative leadership positions. The first section of this review explores the historical perspective of women in educational leadership and demonstrates how stereotypic beliefs and historical trends influenced the crisis facing women today in administration. Following this section, the current status of women in educational administration is examined along with the relevant research and literature impacting the field today. The third section highlights minority women: African American and Hispanic. The barriers facing these two ethnic groups in public school administration are reviewed. The final two sections of this review give a summary of the research existing on the hindrances women face in their ascent up the career ladder and the strategies practiced by women in overcoming these obstacles.

The History of Women in Educational Leadership

Although teaching has been identified as a female profession, teachers have not always been women. If fact, records indicate that until the late eighteenth 
century, most teaching was done by men (Shakeshaft, 1989). In Colonial America, men dominated the most prestigious teaching positions. Women were provided employment in the Dame Schools where they conducted small classes in basic literacy to primary age students (Campbell, 1984). These schools were ranked lower with regard to the importance of the educational experiences provided. Public institutions, secondary schools, academies, and colleges were the exclusive domain of males and were regarded as significantly more valuable to the educational development and growth of the students (Campbell, 1984). Women were considered only transient members of the work force at that time. They were expected to exit the work force once they were married (Ginn, 1989). The social standards at the turn of the century described the superior being as "white, male, middle-aged, Protestant, and married" (Ginn, 1989). This "standard" has been in existence throughout history.

During the early twentieth century, the adoption of scientific management practices produced the separation of management functions from teaching (Altenbaugh, 1987). The division of labor that resulted from scientific management rapidly became the fundamental paradigm for structuring schools (Patterson, 1994). Women assumed the role of teachers and men were placed into management positions over them. In fact, Campbell (1984) reported that the arguments utilized to support this theory were that women had superior 
understanding of small children and that they were more amenable to bureaucratic rule and supervision of male superiors. Also, school leaders believed that hiring women was an economic advantage due to the belief that they could be paid lower wages. Women were generally willing to work for less because other jobs available to them paid even lower. Tyack and Stober (1981) noted that during this period smaller systems usually hired male administrators, while women were sometimes given an opportunity to serve as principals in larger systems. Male superintendents supervised them, however, even in the larger systems. When hired as principals, women typically worked in primary schools and supervised only women. This hierarchy of gender in the public school system has continued to exist in schools today.

Women as teachers became a majority in public schools in the middle decades of the nineteenth century. Campbell (1984) noted that when national statistics became available for the first time in 1870 , the nationwide figures indicated that about $60 \%$ of the teaching force were male. The percentage of women in the profession slowly increased to $70 \%$ in 1900 then peaked in 1920 at $86^{\circ}$. In fact, the involvement of women as teachers and administrators was at an all time high from 1865 - 1920 and during the Depression in the 1930's. (Berman, 1996). Thereafter there was a slow and continuous decrease in the number of females in instruction and educational management, especially during World War 
II when men increasingly entered the field of education and replaced women (Burstyn, 1980; Haven, Adkinson \& Bagley, 1980). According to Gribskov (1980), women represented 55\% of the elementary school principals in 1928 . Kalvelage, Schmuck, and Arends (1978) explained that in 1948 women represented $41 \%$ of the elementary principals, $22 \%$ in 1968 , and in 1973 less than $20 \%$ of the elementary school principals were females. According to the National Center for Education Statistics (1994), the percentage of female principals in public schools increased from $21.4 \%$ in $1984 / 85$ to $30 \%$ in $1990-91$. Based on these statistics, $36.5 \%$ of public elementary school principalships were held by women, while they held only $11.0 \%$ of the public secondary school principalships. As is evident, the trend that predominated during the earlier periods of history still prevails today; women teach students and men administer adults (Ortiz, 1982; Marshall \& Mitchell, 1989).

Therefore, historically, men have dominated the administrative ranks of public schools. The social standards and management practices of the past deemed men as more qualified as managers than women. Women have traditionally held teaching positions. Of the few women who hold administrative positions, a majority of them are elementary school principals. 


\section{The Status of Women in Public Schools Today}

In a 1990 research project sponsored by the US Department of Labor, Women's Bureau, it was reported that although women have been in the labor force for a significant number of years, are more highly cducated than ever, have the necessary technical skills to succeed, and occupy about one-third of all management positions, they are still clustered in the lower levels of management in positions of authority, status, and pay than men (Scandura, 1990). Research shows that the problem of the lack of female representation in higher management positions is not limited to education. Beason (1992) reported that women are less likcly to be found in high levels of management in organizations in the private sector as well. Although women fill nearly one-third of the management positions, they are stuck in jobs with little authority, low pay, and at the bottom of the organization ladder (Morrison \& Glinow, 1990).

This general trend holds true for the field of educational administration. Women are in the majority in school administration graduate programs, and there are more women than men in the teaching ranks of the nation's public schools. Yet there is a persistent absence of women from the highest and most powerful administrative positions in public education (Morie \& Wilson, 1996). Gupton and Slick (1995) report that in education, women have clustered at the supervisory and elementary level positions in district administration, positions typically considered 
to have staff rather than line authority (line positions, unlike staff, have strong links to authority and top-level decision-making in the organization). Despite the fact that female educators are now better qualified with degrees as well as years of experience in the field, data reveal that women are receiving only $65 \%$ of the salary of their male constituents (Waddell, 1994).

McGrath (1992) reported that although the teaching profession is known as a woman's profession, the top three administrative posts in public school education (superintendent, assistant superintendent, and high school principal) remain overwhelmingly filled by males despite a growing body of research attesting to the outstanding potential of women in all administrative positions. Most women teachers who enter administration go initially in specialist ficlds of administration, the elementary principalship, and on to a supervisory position. The male teachers pursuing administrative careers more often move into the assistant principalship of a secondary school, then into the secondary principalship, the assistant or associate superintendency, and follow this path on to the superintendent's position (Shakeshaft, 1989).

Kaplan noted in 1989 that within the decade, the population of public schools would be comprised of one-third minority students; yet school administrators were predicted to remain largely white, male and middle-aged. This has held true. In fact, a 1992 publication by the American Association of 
School Administrators, Women and Minorities in School Administration: Facts and Figures $1989-1990$, strengthens the pertinence of the previous statement. The statistics revealed a modest representation of women and minorities in the suprerintendency, assistant superintendency, and principalship:

\begin{tabular}{|llr|}
\hline Representation in the Superintendency - & Men: & $91.6 \%$ \\
\hline & Minority Men: & $3.5 \%$ \\
\hline & Women: & $4.6 \%$ \\
\hline & Minority Women: & $0.4 \%$ \\
\hline
\end{tabular}

\begin{tabular}{|c|c|c|}
\hline Representation in the Assistant Superintendency - & Men: & $70.8 \%$ \\
\hline & Minority Men: & $8.6 \%$ \\
\hline & Women: & $17.3 \%$ \\
\hline \multicolumn{3}{|c|}{ Minority Women: $3.3 \%$} \\
\hline
\end{tabular}

\begin{tabular}{|llr|}
\hline Representation in the Principalship - & Men: & $65.0 \%$ \\
\hline & Minority Men: & $8.0 \%$ \\
\hline & Women: & $20.6 \%$ \\
\hline & Minority Women: & $6.4 \%$ \\
\hline
\end{tabular}

The data above disclose the dominance of the White male in upper administrative positions throughout the country. Although the percentage of women with the position of superintendent, assistant superintendent. and principal 
shown is miniscule, the representation of minority women is the lowest of the four categories displayed. White males hold a majority of the administrative positions and minority females hold the fewest administrative positions. From the statistics, it doesn't appear as if females are tapping into the "Good Old Boy" network. The limited achievements of the non-minority women shown (compared to that of the minority women and the minority men) must be shared with all women in educational administration. Only then will more parity exist.

Grady (1995) reported that a survey conducted by The Executive Educator and Xavier University showed that women are best represented among the ranks of the elementary school principal $(39.7 \%)$, followed by middle school principals (20.5\%), and high school principals $(12.1 \%)$. The lowest percentage $(10.5 \%)$ of female school administrators work as school superintendents (Natale, 1992). Although the figure displaying the representation of women in the superintendency by the AASA (1992) are slightly lower than that represented by Natale (1992), the percentages of both are still considerably lower than the figures displaying the representation of men in the superintendency. Schuster and Foote (1990) concur by revealing that females hold fewer superintendencies than males and are older when they get these positions. They found that nearly $36 \%$ of the women in their study were over 46 when they got the job. Only $14 \%$ of the males were over 46 when they secured the job. Additionally, more than three-fourths of 
the female superintendents had more than five years of teaching experience while only two-thirds of the male superintendents had more than five years teaching experience. Also in the study by Schuster and Foote, female superintendents reported holding central office positions more often than males (50\% versus $41 \%)$, but fewer principalships than reporting males ( $74 \%$ for women, $85 \%$ for men).

In 1998 Miami-Dade County Public School published a report revealing the discrepancy in the number of women versus men employed in the upper administrative ranks. Of the senior high school principals, $71 \%$ were men and $29 \%$ were women. The underrepresentation continued with the noninstructional personnel (deputy, assistant, associate, area superintendent, and directors, supervisors, and coordinators). It was reported that $61 \%$ of the noninstructional personnel were men while $39 \%$ were women. Females represented the majority only in elementary principalships ( $77 \%$ female compared to $23 \%$ male) and in instructional administrative positions.

Whitaker and Lane (1990) reported that the data on the equality of opportunity in educational administration reveal that gender - more than age, experience, background, or competence - determines the role an individual will hold in education. They also state that these inequalities have resulted in too few women being hired for administrative positions at the local, state. and national 
levels, even though women have always held the majority of the teaching positions.

Females who hold certification in educational administration are largely concentrated in positions as consultants and supervisors of instruction as compared to other positions which require more advanced leadership skills (Bagenstos, 1987). These staff and support positions do not necessarily require advanced degrees when compared to the principalship. These positions are normally assistance oriented and do not require the individual to directly supervise individuals (Bagenstos, 1987).

In a study of female administrators, Bagenstos, (1987) reported that women administrators: (1) attain the principalship at an older age than male principals; (2) teach longer than men do before entering administration; (3) are more likely than men to continue graduate education part-time while serving as principals; and (4) earn less than men in similar positions.

We live in a society in which white men define and legitimate the dominant culture. It is assumed that the white male-defined standards for what constitutes effective leadership are superior (Patterson, 1994). It is also assumed that because the educational values, leadership styles, and day to day activities of women and non-white males are different from white men, such behaviors are deemed 
inappropriate and must be changed (Marshall, 1984; Weber, Feldman \& Poling, $1981)$.

Erwin and Harmless (1995) state that schools are continually coping with declining revenues, lack of innovations, creativity, and risk taking on the part of current administrators coupled with a reluctance to change and a demanding client population. With those stated challenges, they feel that there is a need for a new and more sensitive style of leadership. They feel the role of school personnel is vastly changing and the customer expectations go beyond the academic needs of the students to include social, emotional, physical, and psycholugical needs. Women administrators fit this description.

If one of the tasks of selecting able leaders for public schools in the twentyfirst century is hiring those who have strong instructional skills, can encourage the talents of others, can communicate effectively with multiple constituencies, and can unite diverse citizen groups to solve school problems, then more than $10 \%$ of the nation's superintendents should be women (Morie \& Wilson, 1996). Of the women and minorities who are permitted into the world of higher-level administration in the public schools, few tend to have opportunities for career mobility (Patterson, 1994). They are often assigned to staff positions. administering special projects and/or superrising their own group (Marshall, 1992: Bell \& Chase, 1992). Patterson (1994) concurs by asserting that they are 
frequently given roles as tokens with little or no legitimacy within the organization. Bell and Chase (1992) established that minority and female administrators are typically assigned to special programs or schools with large minority populations; usually with inadequate resources, large concentrations of economically disadvantaged students and concomitant low standardized test scores.

Educational institutions are deprived of the leadership skills and competence of people who happen to be female. Why are the leaders of a femaledominated profession predominantly male? Patterson (1994) asserts that the gender-role socialization of girls and women to assume traditional female roles contributes to their lack of success in a traditionally male-defined career path. This socialization process teaches women to demonstrate passivity, deference, and self - abasement. They are taught not to take risks and not to be ambitious, but to maintain their male-defined femininity. These socially constructed role definitions produce negative consequences for women who have aspired to high-level administration positions. Administrative roles are considered at odds with more traditional women's roles of teaching and motherhood. Women must. see themselves in the role of a leader (Schneider, 1991). 
A study by Morie and Wilson (1996) suggests that the merging of three key factors create women who are ready to apply for a higher-level administrative position:

1. positive self-image as a leader

2. others view them as effective leaders.

3. a wide range of professional experiences in education

Brumer (1993), in a study of highly successful female superintendents, concluded that females who wish to access power circles needed to be "culturally bilingual," i.e. they needed to "speak the language of those in the male circles of power while remaining feminine."

The studies discussed previously have all shown the disproportionate number of females as compared to males in higher-level administrative positions. Scandura (1990), Morie and Wilson (1996), Gupton and Slick (1995), McGrath (1992), and Bagenstos (1987) all confirmed the immense disparity of women in higher-level administrative positions as compared to the larger numbers who are teaching. Bell and Chase in 1992 and Patterson in 1994 cited evidence of women being assigned to segregated positions that have little or no legitimacy. The data provided by the American Association of School Administrators (1992) as well as the data cited by Schuster and Foote (1992), Grady (1995), and the more recent datia provided by Miami-Dade County Public Schools (1998) all provide 
documentation of the insufficient amount of females serving in roles of principal, assistant superintendency and superintendency.

In summary, the status of women in public schools today has not altered very much from that of the past. Statistics show that although women represent the majority in the teaching profession, the top three administrative positions in public schools (high school principal, assistant superintendent, and superintendent) continue to be overwhelmingly filled by men.

\section{Minority Women in Educational Administration}

Female principals are described as usually Anglo and Protestant. They are married, usually having children. They are also often the firstborn or the only child, and are from two-parent homes (Edgin, 1987; Shakeshaft, 1987; Sulowski, 1988). Although women comprise a majority of the nation's public school teaching force, most school administrators are white males. At the highest level in public school administration, which is the superintendency, there seems to be a great deal of resistance to gender and minority integration (Bell \& Chase. 1993). This is true despite the increased pool of highly qualified women.

Gupton and Slick (1995) compared Anglo, African American, and Hispanic female administrators who held the positions of superintendents, assistant superintendents, and high school principals. Anglos represented the largest 
percentage of respondents in all three groups. Eighty-two percent of the assistant superintendents and $88.5 \%$ of the high school principals were Anglo. The greatest percentage of African Americans in the study (8.2\%) was assistant superintendents. Among the respondents, there were only 2.7\% African Americans who were superintendents and $7.7 \%$ who were high school principals. Assistant superintendents $(6.6 \%)$ represented the largest percentage of Hispanics in the study. Unlike the African American females, the next largest group of Hispanics occupied the superintendency (5.4\%). High school principals represented $3.8^{\circ} \%$ of the Hispanic females in the positions of leadership in the profession. The overall percentage of women who represent leadership positions in educational administration is miniscule as it is. Thus, the meager percentage represented by African American and Hispanic women demonstrates how severely underrepresented women of other ethnic groups are in public school administration. This study provides confirmation of the fact that of the women who hold the position of superintendent, assistant superintendent, and high school principal, Anglo women dominate the entirety even though the numbers for all women are insubstantial.

Bell and Chase (1993) reported that the faculty, educational leaders, and board members of the K-12 public schools in the United States do not closely reflect the racial and ethnic diversity of the student body. While $16.1 \%$ of the 
elementary, middle, and secondary students are African Americans, just $8.2 \%$ of the teachers are African Americans and while 9.9\% of the students are Hispanic, only $2.9 \%$ of the teachers are Hispanic. The middle school level was reported to have the highest representation of African American principals (9.3\%) and Hispanic principals (2.1\%). At the highest levels of $\mathrm{K}-12$ administration and policy making, particularly the high school principal, the superintendent and the school board, minorities were even more likely to be missing. Only $4.6 \%$ of the high school administrators were minorities; only $4.2 \%$ of the superintendents were minorities, and among the nation's school board members, $3.4 \%$ of the members were minorities. This study shows, therefore, that the educational administrative leaders of the country do not ethnically and racially represent the students who they serve. This fact alone should commence the promotion of more qualified minorities to higher-level administrative positions.

Feistritzer (1990) stated that the gender and racial stratification in public school administration are becoming more striking and disturbing as the demographics of this country change. Hodgkinson (1991) reported that the demographic picture in this country forecast that the minority population in the United States will increase from $30 \%$ to $38 \%$ between 1990 and 2010. Corresponding with this anticipated student population increase is a projected need to hire more women and minority administrators. The National Association of 
Secondary School Principals (NASSP) reported in 1988 that $35 \%$ of the then current high school principals were 50 years of age or older, suggesting that a substantial number of high school principals would be eligible for retirement within the next 10 to 15 years. The data also indicated that the average age of high school principals was higher in larger school districts and communities. This could greatly affect the hiring of minority females in many school districts. The later statistical data (Bell and Chase, 1993; Gupton \& Slick, 1995; and MDCPS, 1998) revealed that this has not been the case. Despite the projections of the NASSP in 1988, the hiring and promotional practices of school districts have not changed as projected. Minorities and women, as has been shown in this literature review, are still not represented appropriately in higher administrative positions.

African American Women and Educational Administration

Howard-Vital and Morgan (1993) state that African American women are still perceived by many to be the least powerful in society and in most organizations. They rarely enjoy positions of power or experience the inner workings of an organization from the vantagepoint of an insider. In the past, males have dominated leadership positions in the African American community typically obtained through education or the church. Adding to the difficulty in obtaining success in the educational community are the myths of the "Black 
mammy" which limit power or options in organizations by painting a onedimensional picture of the African American female leader as being a mother, trusted confidant, compassionate and loyal subordinate, and pillar of strength for others in the organization (Dumas, 1979). This leads to long work hours with heavy workloads performed in front of scrutinizing eyes (Carter, Pearson \& Shavlik, 1988). African American females who attempt to handle the workloads while confronting the stereotypic expectations of others, are challenged to develop identities and credibility within organizations (Dumas, 1979). Carter, Pearson and Shavlik (1988) felt that African American women, despite their numbers in the educational community, are the "most isolated, underused and consequently demoralized segment of the academic community."

In a study conducted by Gill and Showell (1991), demographic data on African American females in Maryland showed that there were documented sexual and racial barriers which prevented the African American female from obtaining top leadership roles in education. Their findings showed that many believed that the politics, friendships, network systems, and other factors outweighed the qualifications of education and experience in determining whether a job/position adrancement occurs. Fontaine and Greenlee (1993) reported that on many occasions, being the only member of a sex and racial group in the workplace, African American women feit they had to outperform majority group counterparts. 
Jones (1993) suggests that for African American female administrators, who are most often the "only one," the first, or even a token minority within their divisions, the unspoken must be observed carefully. It means that the comments or behavior of these individuals tend to be enlarged and generalized to groups they represent. Second, the individuals often experience social and professional isolation, often leading to feelings of loneliness. Third, they often encounter false assumptions and stereotypes. Fourth, the individuals are expected to serve on multiple committees within their division to represent a minority perspective. Lastly, White and male privilege, racism, and biases are an accepted, if unrecognized norm. For African American females, self-validation sometimes may be the only source of acknowledgement received (Phelps, 1995).

From the stereotypes described by Dumas (1979), to the study results demonstrating promotional disparities reported by Gill and Showell (1991), Fontaine and Greenlee (1993), and Jones (1993), all point to the same critical factor for African American females. That factor as established by Hawkins (1993) states that "Nobody takes care of the African American female, we take care of ourselves. It's not fair, but that's the way it's been for hundreds of years." 


\section{Hispanic Women and Educational Administration}

The research on Hispanic female administrators is very limited. Carr (1995) conducted a series of extended interviews with Mexican American female principals in the Rio Grande Valley region of Texas. With these women, the concepts of leadership, power, and caring were explored in the context of a predominantly Mexican American community culture. This culture represented a community that cherishes family, values, and the nourishment of traditions. The women described the difficulties of finding their balance between being Mexican American and female. The leadership styles of these Hispanic female principals practiced aspects of management not utilized by Anglo males. Those included collaboration, teamwork, shared decision making, and a tolerance for diversity.

Burgos-Sasscer (1990) reported that by the year 2000 there would be at least 30 million Hispanics in the United States. She also reported Hispanics as being the fastest growing minority group as well as the youngest. Hispanics will comprise $39 \%$ of the workforce by the turn of the century. Burgos-Sasscer (1990) asserted that educational institutions must provide environments where Hispanic people can learn and develop their potential to the fullest. Role models and sensitive administrators are a must. Increasing the number of Hispanics in top level administrative positions is a compelling need that must be satisfied. 
In a case study of the career paths, barriers and strategies of six Hispanic female school administrators, Regules (1997) describes the typical Hispanic female staff administrator as beginning her career as a bilingual teacher. The path then moves to a bilingual resource teacher position, then proceeds to district administration before becoming an assistant principal. Eventually, the Hispanic female returns to the district level as a director before ultimately advancing to the assistant superintendency. She describes the typical Hispanic female line administrator as beginning with the position of bilingual teacher, moving to a bilingual resource teacher position, proceeding to district administration, and then becoming an assistant principal. Eventually, she becomes a site administrator, then returns to the district level as a director before ultimately advancing to assistant superintendent. The subjects in Regules' study were three Hispanic female line managers and three Hispanic female staff managers and their mentors in California public schools in Monterey, San Benito, and Santa Cruz counties.

Gorena (1996) conducted a national survey investigating the perceptions of Hispanic women administrators in higher education concerning the factors that positively influenced or hindered their advancement to leadership positions. The five major factors in which the Hispanic female administrators viewed as positively influencing their career advancement included education and training, goal-setting, networking, knowledge of mainstream systems, and knowledge of the 
advancement process. Traditional Hispanic cultural values such as family traditions and the stereotypical view of the female as being subordinate and ethnicity were seen to hinder advancement. Within the category of family factors, personal economic status, parental economic status, and children were perceived to positively influence the advancement process. Household duties and other family responsibilities were seen as hindrances. In the support category, family/friends, colleagues/peers, spouse/significant others, and non-Hispanic administrators were identified as positive influences, and institutional staff (those who represented the hierarchy in the school system) were seen as hindrances.

A study conducted by Ornelas (1991) to determine the variables most relevant to upward career mobility of Anglo and Hispanic female school administrators discovered that women, especially Hispanics, were not equally represented in central administrative positions. The directorship position was the highest position held by the participants surveyed. Most Hispanics were reported as occupying elementary principalships and were usually assigned to predominantly minority schools. In the study, the Anglo women expressed a greater satisfaction with the progression of their careers than did the Hispanic women. The Hispanic women aspired to higher career goals than did the Anglo women. The Hispanic group, more than the Arglo group, attributed their career success to intentional change, and also gave themselves the greater portion of the 
credit for choosing, planning, and carrying out the change to become administrators.

The studies on the Hispanic female described have a significant resemblance to those previously discussed about the African American female. The studies by Carr (1995), Burgos-Sasscer (1990), Gorena (1996), Regules (1997), and Ornelas (1991) all demonstrate that the Hispanic female administrator faces the same barriers as the African American female. They both must overcome traditional customs, minority female stereotypes, and the "Good Old Boy" network established by the White male.

Iii conclusion, minority female administrators (African American and Hispanic) are severely underrepresented in higher-level administrative positions in the nation's school systems. When given principalships, they usually occur at minority elementary schools. As the demographics in this country change, there is a need for an increased female minority representation in the positions of high school principal, assistant superintendent, and superintendent. Although the research on Hispanic female public school administrators is limited as compared to that of the research on African American female public school administrators, representation of both groups is in dire need due to the control exercised by the White males in higher-level administrative positions. 


\section{Barriers to Career Advancement}

Barriers to women's advancement are informal as well as formal. Formal barriers, such as preparation and certification, may not be as imposing as the informal ones, such as inclusion and association with the center of power in organizations (Restine, 1993). Beason (1992) classified barriers into two categories: internal barriers and external barriers. Internal barriers are defined as obstacles within women; external barriers are obstacles from socicty and the structure of the organization. The informal barriers described by Restine may by correlated with the external barriers characterized by Beason. Both types of barriers would include deterrents such as sex discrimination, exclusion from the "old boy's" network, negative attitudes toward women in administration, lack of role models, and lack of professional networks. The formal barriers and the internal barriers do not play significant roles in the advancement of women.

The inapplicability of the internal barriers to the female administrator of today is evidenced in the research conducted by Jones \& Montenegro (1982), Ortiz and Marshall (1987), and Shakeshaft (1985). They describe internal barriers as a lack of assertiveness and a reluctance to take risks. Internal barriers also include having a poor self-image and a lack of self-confidence. Having conflict or confusion regarding life goals and having a lack of motivation and a low professioual perseverance in pursuing these goals also characterize internal barriers. Lastly. 
internal barriers are depicted by the researchers as those involving a lack of preparation or experience, a fear of success, and a state of ambivalence. Shakeshaft (1987) labeled internal barriers as an outgrowth of a social context in which White males hold power and privilege over all other groups. He also asserted that the internal barriers focus on women's inadequacies, and make it seem that if women would change themselves the problem would be solved. $\mathrm{He}$ feels that it is an attempt to blame the victim (women) for the lack of achievement in administration and ignore the external barriers and forces.

Berman (1996) reported that internal conflict is often brought to the workplace and in many instances creates a barrier that is very hard for women administrators to penetrate. Berman also stated that even though women may have the necessary foundation for understanding their socialization process and may possess positive self-concepts, the standard used to measure them is the white male.

Woo (1985) concluded that many women found psychological separation and alienation from the rest of the organization too much to bear. Woo drew the conclusion that what American women need to understand is that they can be career women. mothers, sex symbols, fashion plates, and community leaders, but not all at the same time without some personal stress. Gupton and Slick (1995) found in their study on women administrators that the women overwhelmingly 
(68\%) indicated that balancing career and family was among their most challenging career obstacles.

Most authors (Edson, 1981; Moore, 1984; Bell \& Chase. 1992) recognized external barriers as more influential than internal barriers. Jones and Montenegro (1982) define external barriers as resulting from society's attitudes and the structure of the organization. These barriers require social and institutional change (Shakeshaft, 1987). Beason (1992) lists the external barriers as consisting of four types. The first, interpersonal barriers, involve the sometimes-strained relationships with fellow administrators. The second, socialization and sex-role stereotyping involves the roles society feels women should portray. Those roles conflict with the role of being an administrator and a leader. The third barrier is sex discrimination. This barrier includes the restrictions placed on women by the educational organization and by society in general. The last barrier involves the structure of the organization. This barrier describes the limitations the composition of the organization places on the advancement of the female. Unfortunately, in educational administration, the avenues available for advancement are limited.

Greyvenstein and van der Westhuizen (1991) cite many barriers that have been identified as affecting the status quo of women in educational administration. These include societal perspectives of women, gender career options and patterns. 
historical and current gender trends on horizontal and vertical continuums in the education profession, and numerous overt and covert intrinsic and extrinsic factors which function on individual, organizational and societal levels. Greyvenstein and van der Wethuizen ccnclude that as a result of the many barriers, the reasons for the current position of women in educational management are complex and diverse. They state that the socialized stereotyping of traditional gender roles and the associated attitudes of both males and females are the major reasons for the lack of career advancement of female administrators.

Crutcher (1992) examined the barriers that affected the upward mobility of women administrators in the state of Alabama. She concluded that the most frequently reported barriers to upward mobility for all categories of female principals in her study were as follows:

1) Women believe that they will be considered unfeminine if they confront conflict assertively.

2) A major barrier to a woman's career is her need to give primary attention to her family until the youngest child is in school.

3) Women do not have a "good old girl" network.

4) Women find psychological separation and alienation from the rest of the group difficult to experience.

5) Women build self-esteem and confidence by associating with a mentor. 
Restine (1993) felt that the fact that more women occupy the elementary principalship and the central office position has become a barrier to career advancement due to the view that both positions have become dead-end posts. These positions are not as publicly visible as the superintendency or the high school principalship.

In attempting to advance, women in administration and management encounter what has been labeled as the "glass ceiling" (Johnson, 1991; Knox, 1991; Morrison \& Glinow, 1990). Beason (1992) describes the "glass ceiling" as a barrier so subtle that it is transparent, yet so strong that it prevents women and minorities from moving up in the management hierarchy. Obstacles that make up the "glass ceiling" have all been described above as the external barriers that women must face. In educational administration, women may advance to the position of elementary principal or curriculum leader. Their progression many times ends there. They can only go so far, and then they hit the "glass ceiling." Scandura (1990) states that the glass ceiling for women may be even lower than other studies have indicated.

The barriers to career advancement have been categorized as formal and informal by Restine (1993), and internal and external by Beason (1992). Shakeshaft (1987), Berman (1996), Bell and Chase (1992), Moore (1984), Jones and Vontenegro (1982), and Edson (1981). Most authors concede that external 
barriers have played a greater role in the advancement of women than internal barriers. Many women overcome the internal barriers in the process of advancing to their present positions as elementary school principal or curriculum leader, but it is the external barriers that hinder them from further advancement as secondary school principal, assistant superintendent, or superintendent. Those external barriers make up the "glass ceiling" described previously. The question remains now as to how women break through the "glass ceiling" and overcome those external barriers.

In summary, the barriers to career advancement have been classified as informal and formal, as well as internal and external. External barriers have been reported to play a greater role in the advancement of women than the others. A few of the external barriers are interpersonal barriers, sex-role stereotyping, sex discrimination, historical gender trends, and the "glass ceiling."

\section{$\underline{\text { Strategies Utilized to Overcome Barriers }}$}

Moire and Wilson (1996) list four key factors which may assist women in overcoming the barriers to career advancement in educational administration. Having powerful motivation is the first factor. The second factor is having successful career-family configurations. Third, haring guidance from mentors and spouses. Lastly, those women with extraordinary perseverance who have the 
determination, persistence, and tenacity that it requires to succeed despite the innumerable deterrents that are imposed on them have succeeded in overcoming the barriers to career advancement. Certain strategies have been described as being utilized to get past the perceived barriers (Morie \& Wilson, 1996). The first strategy is obtaining proper credentials such as the doctorate degree. The second strategy is becoming more persistent about career goals and not allowing obstacles to deter ambition. The third strategy is watching successful male superintendents as they advance. The fourth strategy is obtaining and following the advice of gatekeepers, mentors, or sponsors. The fifth strategy is not ailowing family circumstances to hinder mubility. Last, maintaining a positive attitude about the future is important.

The need for mentorship or sponsorship has been strongly reinforced in the literature as a strategy in which all aspiring female administrators should take note. In a study by Berman (1997) on the barriers faced by female administrators, the statement with which her respondents strongly agreed was that mentors can help women's careers by giving their protegees career direction, support, career aspiration and by assisting with career change. Whitaker and Lane (1990) stated that mentoring must occur for women to succeed in acquiring administrative positions in education. They reported that through mentors, women could receive 
practical experiences, knowledge about job openings, "inside" information about positions and districts, as well as encouragement and advice.

Whitaker and Lane (1990) asserted that for women to succeed in acquiring administrative positions in education, mentoring must occur. They reported that there were two issues that influence whether women have mentoring relationships in public schools. First, opportunities for women to have mentors are limited by the scarcity of women who occupy appropriate positions in administration. Also, cross-mentoring, when it does occur between male mentors and female protegees, is frequently of reduced value or importance because of sex role attitudes. Therefore, women currently in administration must try doubly hard to mentor other females who wish to enter administrative ranks. Brown and Merchant (1993) state that women being mentors to others is a critically important aspect of increasing women's support systems.

Findings by Gupton and Slick (1995) support the importance of mentoring. Their results confirmed that the majority of the highly successful women educators have had significant numbers of positive role models and supportive mentors in their lives. Considering the scarcity of mentors available to women: the successful women in educational administration are the fortunate ones who have had outstanding support from mentors. 
Grady (1995) noted that a sponsor could be helpful in a career by providing encouragement to enter administration or preparing for an upward move on the career ladder. In addition, Grady states that a sponsor could provide inside information to which the aspiring candidate may not have access and could provide insight to job-related opportunities.

Moire and Wilson (1996) discovered in a study of female superintendents that the subjects had mentors in all areas of their lives: professor mentors in doctoral programs, on-the-job principal and superintendent mentors, and spouse mentors. Those mentors provided different types of support for the women. Professor mentors acknowledged the intellectual and leadership abilities, suggested the women could be successful in an administrative job, pushed the women to complete doctorates, linked them with networks of contacts, and gave them recommendations. Principal mentors acknowledged the women's leadership abilities and gave them challenging administrative responsibilities. Superintendent mentors took the women to regional leadership meetings, helped them obtain critical administrative experiences, and gave them chaflenging administrative assignments.

A career plan is also important for aspiring female administrators. (Beason. 1992). Setting career goals and formulating a plan of action have been identified as strategies utilized by women to overcome personal barriers (Jones \& 
Montenegro, 1982). Other researchers have indicated that it is essential to have a definite career plan, to be prepared, qualified, and certified (Clemens, 1990: Edson, 1988; Truesdale, 1988; Warren, 1990).

Participation in professional and community organizations has also been identified as an important strategy for women (Truesdale, 1988). This strategy can expand opportunities for female administrators to network with those who determine accessibility to the system as well as the various filtering mechanisms designed to weed out all but the most competent (Bowman, 1987).

Networking is an important strategy for advancement as well. This can lead to the development of an "old girl" network (Beason, 1992). Networking can be formal or informal. It can serve to provide information on vacancies, workshops and conferences, along with support, feedback, encouragement, advice, and insight (Blum, 1990).

Another key strategy for women looking for administrative positions is to become professionally visible (Edson, 1988). Ortiz labeled becoming visible as "G.ASing, Getting the Attention of Superiors" (1982). This includes obtaining recognition of superiors for programs that were launched, success stories that inspire, or any accomplishment or achievement that showcases the potential of the female administrator. Through GASing and engaging in administrative activities. 
female administrators can acquire the experience, knowledge and skills necessary (Ortiz, 1982).

The results of a 1997 study by Berman concur with the previous research cited. The respondents in her study described one of the professional development and training needs as mentoring. This corresponds with research conducted by Whitaker and Lane (1990), Brown and Merchant (1993), Gupton and Slick (1995), Grady (1995), and Moire and Wilson (1996). Another professional development and training need described is having the opportunity to meet with other administrators to discuss issues. This agrees with Beason's description of the necessity for the development of an "old girl" network (1992). Previous research conducted by Moire and Wilson (1996) correlates with Berman's description of the need for on-the-job training, leadership training, and the development of selfconfidence.

Braun (1995) conducted research on developmentally appropriate administrative leadership learning experiences for women given their particular learning styles. He concluded that such a program benefiting women would have. characteristics such as being conducted using interactive styles with the participants and engaging in dialogue, discussion, and reflection. The program would also center on principles that could be applied over time in many settings. There would be a focus on the individuals participating in program. The program 
should be based on research and supplemented with the personal experiences and perspectives of the participants. It would be conducted using a variety of learning methodologies to account for differences in learning styles. Lastly, a program focusing on the developmentally-appropriate administrative leadership learning experiences for women given their particular learning styles would be evaluated with a variety of tools that allow the participants multiple means of feedback.

In summary, so that female administrators may overcome obstacles to career advancement, they must engage in tactics to master the hindrances that others place before them. Having positive role models, seeking mentoring relationships, and networking (forming a "New Girl" Network) are three that are cited repeatedly in literature. Others include having a career plan, participating in professional organizations, and becoming professionally visible.

\section{Conclusions}

The research in this literature review has shown that the standards for the superior administrator has always been the white male (Ginn, 1989). This standard has been reflected in the statistical data reported by Schuster and Foote in 1990, the American Association of School Administrators in 1992, Grady in 1995. and Miami-Dade County Public Schools in 1998. Those studies revealed the depth of the deficiency of women in educational administration. With this barrier in 
place, it has been particularly difficult for minority women to progress to higher administrative positions (Gupton and Slick, 1995). Many barriers have been identified as hindering the advancement of women. The most prominent barrier is the external barrier (Shakeshaft, 1987; Beason, 1992; Bell and Chase, 1992; and Gupton \& Slick, 1995). The strategies utilized in overcoming these barriers include obtaining a mentor (Berman, 1997; Whitaker \& Lane, 1990; Brown \& Merchant, 1993; Gupton and Slick, 1995; Grady, 1995; and Moire \& Wilson, 1996), developing a career plan (Beason, 1992; and Berman, 1997), and networking (Blum, 1990; Beason, 1992: and Berman, 1997).

Given the historical placement of men in educational administrative positions, women would be wise to develop leadership skills that could give them an advantage in the competition for positions of power - positions where women can make a difference in the lives of students, their families, teachers and school staff - positions that can make a difference for our communities and our country (Braun, 1995). The prevalence of a paucity of women in the upper administrative ranks shows only minimal signs of abating. A common plan of action is in dire need.

Albino (1992) sums up the status of women in educational leadership by stating, "Conventional wisdom says women are at a disadvantage :a moving ahead in management. We do not have the same social skills as men, and we have not 
been playing the game as long. The fact is, there are many different ways to win; it all depends on how you play the cards you've been dealt. And you don't need dirty tricks; you just need to know the rules of the game." 


\section{Chapter Three - Research Design and Methodology}

This study investigated differences among African American, Hispanic, and Anglo women on the barriers and strategies perceived as significant factors to career advancement in educational administration. This study alsc examined the effects of the barriers that were perceived to be related to career advancement. In addition, personal and professional characteristics of the respondents were investigated to determine whether these factors significantly influenced their perceptions of obstacles, the effects of obstacles, or the strategies utilized to overcome the obstacles that hindered their careers. The study, descriptive in nature, utilized several statistical techniques to obtain and analyze data for the investigation. The major statistical procedures used in the study to explore the relationships between variables included basic descriptive statistics, cross tabulations with chi square, analysis of variance (ANOVA), and post-hoc (Tukey's) tests. This chapter presents a description of the procedures followed during data collection and analyzation. Specifically discussed are the target population, the data collection methods. and the data analysis procedures. 


\section{Target Population}

The target population was chosen from 574 male and female administrators with the position of principal or higher employed with Miami-Dade County Public Schools in Miami, Florida. Females with the position of principal, director, region superintendent, associate superintendent, assistant superintendert, and deputy superintendent were identified as the target population. The pay scale (pay-grade) employed by Miami-Dade County Public Schools determines the status of the position held. Principals begin with a pay scale of 47 . As the administrator advances, the pay scale increases (see Appendix E). Those with a position lower than that of a principal are on a lower pay scale. The identified positions were chosen due to their pay-grade status of 47 or higher.

The subjects were identified and verified from a listing of eligible employees provided by Miami-Dade County Public Schools. The final count included 153 females in the elementary principal position, 21 in the middle school principal position, and 10 in the senior high principal position. The other totals included 64 with the position of director, and 12 with the position of either region superintendent, assistant superintendent, associate superintendent, or deputy superintendent. The total sample was 260 female administrators of paygrade 47 or higher. 


\section{Instrumentation}

The data gathering tool for this study was a survey questionnaire developed by Myrtle V. Campbell, Doctor of Education degree, Indiana University, 1984. Dr. Campbell conducted a pilot study with female administrators in two school districts in Indiana to determine needed changes in the instrument before full-scale administration took place. She utilized suggestions from the reviewers and the respondents' evaluations of the preliminary questionnaire in preparation of the final study questionnaire. The preliminary questionnaire for the study was also reviewed and critiqued by the chairman of her committee and by her committee members. Research specialists in the departments of educational administration and psychology at Indiana University and a computer program specialist also analyzed the survey instrument. Dr. Campbell made efforts to determine the relevancy of each item to the study. She chose the items for use in the instrument on the basis of several critical questions:

a) Was the item relevant to the objectives of the study?

b) Did the item economize the effort and time of the respondent?

c) Did the item allow for exceptions and diversity of response?

d) Was the construction of the instrument appealing to the respondent? 


\section{Format of the Questionnaire}

The questionnaire consisted of 49 items requiring categorical responses, open-ended responses, a Likert-type response, and a voluntary short answer item (see Appendix D).

Parts I and II of the questionnaire were to clicit information about the respondents' personal and professional characteristics in order to provide a composite profile of the administrators. The data derived from these sections were analyzed to determine the relationship between these variables and the respondents' perceptions of barriers, the effects of the barriers, or the success rate of specific strategies. Question 11 of Part II was designed to determine the position-seeking assertiveness and the ultimate aspirational level of the respondents. The response to this question was viewed as an indication of the respondents' goal orientation and both an understanding of opportunities for and to routes to career advancement. Question 12 of Part II assessed the respondents' perceptions of their professional success in relation to their position title, providing some insight into the respondents' job satisfaction and perceptions of their professional strengths and weaknesses.

Part III ascertained information regarding respondents' perceptions of internal and external barriers to career advancement. This section consisted of 17 
items requiring a seven-category Likert-type response indicating whether each barrier was Not a Factor to a Serious Factor in their career advancement.

Parts IV and V also required Likert-type responses and provided data on the respondents' perceptions of how the barriers affected their career advancement and the success rate of the strategies utilized in accomplishing career goals.

\section{Data Collection Method}

In November 1998, the questionnaires for the study were mailed through U.S. mail to the 260 female administrators identified in the selected positions. A cover letter accompanied the instrument explaining the study and requesting the voluntary participation of the subjects (see Appendix B). Respondents who were interested in receiving a copy of the study's results were asked to complete an information form included with the questionnaire. A special thank you pencil and a stamped return envelope were provided for convenience.

Follow-up questionnaires were sent to those not responding to the initial mailing in December, 1998. After two weeks, the remaining non-respondents received a phone call as a reminder.

The total number of higher-level female administrators who responded was 175 representing a $67 \%$ return rate. 


\section{Data Analysis}

Information gathered from the questionnaire was used to create a database to facilitate return monitoring and data analysis. Frequency distributions and measures of central tendency of administrators' personal and professional characteristics were compiled to provide a composite profile of African American, Hispanic, and Anglo administrators. The frequency tables prepared for displaying variables on the questionnaire included the absolute frequency of each response and the relative frequency of each response (in percentages). Measures of both central tendency and dispersion were computed in the analysis of data for items with continuous variables (Sections III, IV, and V, items 13 through 55). Dimensional tables were prepared for displaying cross-tabulations of administrators' personal and professional characteristics to ascertain similarities and differences among respondent variables by ethncity.

Analysis of Variance (ANOVA) was the principal statistical technique used to analyze the data on perceptions of barriers, effects of barriers, and strategies among African American, Hispanic, and Anglo females. For all items with a significant overall F-ratio ( $\mathrm{p}<.05$ ), Tukey's tests for post-hoc comparisons were employed to identify ethnicities with means significantly divergent from those of other ethnicitizs. 
Data collected on perceived strategies were cross-tabulated to compare the frequencies of respondents' use of specific strategies by ethnic group. Barriers, effects, and strategies were further rank-ordered according to perceived significance for each ethnic group.

The responses to the open-ended and short response items were analyzed and grouped into categories for presentation. The data and results of the analysis were reported in narrative form. 


\section{Chapter Four - Presentation of Data}

The study results represent the comprehensive information obtained from all questionnaires received in November and December, 1998 from 156 higherlevel female administrators employed in Miami-Dade County Public Schools. Miami, Florida. The population for the study was defined as full-iime female administrators employed either as principals, directors, region superintendents. assistant superintendents, associate superintendents, or deputy superintendents in Miami-Dade County Public Schools as of November 1998. Of the 260 female administrators identified in the specified positions, 175 returned surveys. Nineteen of the administrators returned surveys that were either unmarked or stated assistant principal as the position title, resulting in the elimination of the survey. This yielded a total return rate was $67.31 \%$ for all questionnaires of which $60 \%$ were usable.

For the purpose of correlating with the ethnic classifications on the questionnaire, in this chapter African American will be referred to as Black/Non Hispanic and Anglo will be referred to as White/Non Hispanic. Of the surveys returned, 156 were valid for analysis. Of those who returned usable questionnaires for the study, 49 were White/Non Hispanic, 50 were Black/Non Hispanic, 54 were Hispanic. two were multiracial, and one identified herself as "other." The same 
population consisted of 104 elementary school principals, 14 middle school principals, three senior high school principals, 15 directors, three assistant superintendents, one deputy superintendent, and 16 other non-school site higherlevel administrators. The results of the study were based on the comprehensive information of all questionnaires received from these respondents.

The survey was organized into five sections. Sections I and II provided information regarding the personal and professional characteristics of female administrators who were employed as elementary school principals, secondary school principals, directors, assistant superintendents, associate superintendents, and deputy superintendents. The third section was based on the respondents' perceptions of barriers that impeded their advancement in school administration. The fourth section reported on the perceived effects of barriers and their influence on the administrator's career development. The final section identified specific strategies reported as successful in surmounting many of the barriers. A voluntary section at the conclusion of the survey asked for additional comments on any of the areas surveyed in the narrative form.

To analyze the respondents' personal and professional characteristics, cross tabulations were conducted on the demographic information given as well as on the final section identifying the specific strategies reported as successful. One Way Analysis of Variance (ANOVA) was conducted on sections three and four 
that provided information of the barriers to career advancement and the perceived effects of the barriers by ethnicity. For the items with a significant overall F-ratio $(p<.05)$, Tukey's test for post-hoc comparisons was utilized to identify groups with means significantly divergent from those of other ethnicities.

In the analyses of the respondents' personal and professional characteristics, the very small numbers represented in certain categories made it impossible to make meaningful comparisons. Therefore, the ethnic group categories of Multiracial; Asian, and Other, along with the degree category of Bachelors were eliminated due to the meager representation. The results of analyses from the research are displayed in tables and narrative form.

$\underline{\text { Reliability Analysis }}$

Gay (1996) refers to reliability as the degree to which the rating scales measure the targeted phenomenon consistently. The internal consistency of the instrument was chosen as the appropriate form of reliability. Internal consistency refers to the degree to which the items have been grouped together conceptually as subscales correlate with each other. The acceptable standard of reliability for behaviorally anchored rating scales should be set at .80 when assessing the internal consistency of the instrument (Gay, 1996). The reliability analysis was divided into three subscales. Gay (1996) also states that if a test is composed of 
several subtests, then the reliability of each subtest, not just the reliability of the total test, must be assessed. Since reliability is a function of test length, the reliability of a given subtest is typically lower than the total test reliability. The reliability was established for this study using Cronbach's Alpha. The overall Cronbach's Alpha reliability coefficient for the total test was .836 , refiecting a high level of internal consistency. The Cronbach's Alpha reliability coefficient of the 17 questions of the first scale relating to the perceived barriers experienced by female administrators was .946 . The Cronbach Alpha reliability coefficient of the ten questions of the second scale relating to the effects of the perceived barriers was .855 . Lastly, the Cronbach's Alpha reliability coefficient of the ten questions of the third scale relating to the strategies utilized to overcome the perceived barriers was .708 . Overall, the total test and two of the three scales were internally consistent.

Personal and Professional Characteristics of Administrators

The data from the personal and professional characteristics provided by the respondents were tabulated and analyzed in order to provide a complete picture of each category of the higher-level female administrator and to highlight any differences and similarities between and within ethnic groups. Additional information regarding a description of each group was gathered through several 
cross-tabulations with selected demographic variables. The ethnic subgroups were further analyzed in the study to determine whether there were any differences between each group in how they responded to the questions regarding the perceptions of barriers, their effects, and the success rate of strategies in accomplishing career goals.

\section{$\underline{\text { Personal Factors }}$}

Ethnic Distribution of Administrators

The ethnic composition of the higher-level female administrators who responded included $49(31.4 \%)$ White/Non Hispanic, 50 (32.1\%) Black/Non Hispanic, 54 (34.6\%) Hispanic, 2 (1.3\%) Multiracial, and 1 (.6\%) Other. Of the White/Non Hispanic respondents, $30(61.2 \%)$ were elementary school principals, 5 (10.2\%) were middle or senior high principals, and $14(28.6 \%)$ were non-school site administrators (directors, assistant superintendents, associate superintendents. deputy superintendents). Thirty-five (70\%) elementary school principals, $6(12 \%)$ middle or senior high principals, and $9(18 \%)$ non-school site administrators represented the Black/Non Hispanic respondents. Of the Hispanic respondents, 36 $(66.7 \%)$ were elementary school principals, $6(11.1 \%)$ were middle or senior high principals, and $12(22.2 \%)$ were non-school site administrators (see Table 1). 
Number of Years Teaching

There was a significant difference shown in the number of years teaching prior to obtaining an administrative job by ethnicity, $\underline{F}(2,148)=3.71, p=.027$. Black/Non Hispanic higher-level female administrators had significantly more years teaching $(\mathrm{m}=15.1)$ prior to obtaining an administrative position than White/Non Hispanic higher-level female administrators $(\mathrm{m}=11.78)$. Hispanic female administrators had a mean number of years teaching of 12.47 and did not differ significantly from Black/Non Hispanic female administrators or White/Non Hispanic female administrators. 


\section{Table 1}

Job Titles of Females With Higher-Level Administrative Positions by Ethnicity $\underline{N=153)}$

$\underline{\text { Variable }}$

White/Non

Black/Non Hispanic

Hispanic Hispanic

$\underline{N} \quad \% \quad \underline{N} \quad \% \quad \underline{N} \quad \%$

Job Title

\begin{tabular}{lcccccc} 
Elem. Principal & 30 & 61.2 & 35 & 70.0 & 36 & 66.7 \\
Middle Principal & 5 & 10.2 & 5 & 10.0 & 4 & 7.4 \\
Senior Principal & 0 & 0.0 & 1 & 2.0 & 2 & 3.7 \\
Director & 4 & 8.2 & 7 & 14.0 & 4 & 7.4 \\
Asst. Superintendent & 1 & 2.0 & 0 & 0.0 & 2 & 3.7 \\
Deputy Superintendent & 0 & 0.0 & 0 & 0.0 & 1 & 1.9 \\
Other & 9 & 19.4 & 2 & 4.0 & 5 & 9.3 \\
Total & 49 & 100.0 & 50 & 100.0 & 54 & 100.0 \\
\hline
\end{tabular}

Age Distribution of Administrators

The age range of the respondents was divided into two categories: those who were 44 years of age and younger. and those who were 45 years of age and older. The reason for the age division was due to the equalization it provided when 
analyzing the age at which the administrators were appointed to their present administrative positions. There was no significant difference shown in the age ranges of the respondents by ethnicity, $p=.65$. Of the White/Non Hispanic administrators, $9(18.4 \%)$ were 44 years of age or younger and $40(81.6 \%)$ were 45 years of age or older. Eleven $(22 \%)$ of the Black/Non Hispanic female adninistrators were 44 years old or younger while $39(78 \%)$ were 45 years old or older. Of the Hispanic respondents, $14(25.9 \%)$ were 44 years old or younger while $40(74.1 \%)$ were 45 years old or older (see Table 2).

\section{Marital Status of Administrators}

A significant difference was shown in the marital status of the higher-level female administrators by ethnicity $\mathrm{p}=.005$. Of the Hispanic administrators, 40 $(76 \%)$ were married, while $32(68 \%)$ of the White/Non Hispanic administrators were married, and only $22(46 \%)$ of the Black/Non Hispanic administrators were married. A greater percentage of Black/Non Hispanic administrators were divorced with $18(38 \%)$ reporting being divorced, while only $6(13 \%)$ of the White/Non Hispanic administrators and only $6(11 \%)$ of the Ilispanic administrators reported being divorced. Of those who reported being single, were $9(19.1 \%)$ of the White/Non Hispanic administ:ators, $8(16.7 \%)$ of the Black/Non 
Hispanic administrators, and $7(13.2 \%)$ of the Hispanic administrators (see Table 2).

$\underline{\text { Table } 2}$

Age and Marital Status of Females With Higher-Level Administrative Positions by Ethnicity

White/ Non

Hispanic
Black/Non

Hispanic
Hispanic

$\underline{N} \quad \underline{N} \quad \underline{0}$

$\underline{\text { Variable }}$

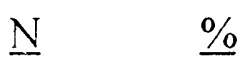

$\underline{\%}$

$\underline{N}$

Age

\begin{tabular}{lcccccc} 
Under 45 & 9 & 18.4 & 11 & 22.0 & 14 & 25.9 \\
Over 45 & 40 & 81.6 & 39 & 78.0 & 40 & 74.1 \\
\cline { 2 - 7 } Total & 49 & 100.0 & 50 & 100.0 & 54 & 100.0
\end{tabular}

Marital Status

$\begin{array}{lcccccc}\text { Single } & 9 & 19.1 & 8 & 16.7 & 7 & ! 3.2 \\ \text { Married } & 32 & 68.1 & 22 & 45.8 & 40 & 75.5 \\ \text { Divorced } & 6 & 12.8 & 18 & 37.5 & 6 & 11.3 \\ \text { Total } & 47 & 100.0 & 48 & 100.0 & 53 & 100.0\end{array}$

Note. Age: $X^{2}(2, \underline{N}=153)=.85, p=.65$.

Marital Status: $X^{2}(4, \underline{N}=148)=14.69, p=.005$ 


\section{Administrators With Children Living at Home}

There was a significant difference shown in the female administrators by ethnicity who reported having children living at home, $p=.004$. Thirty-five (71\%) of the White/Non Hispanic female administrators reported having no children living at home, while only $30(60 \%)$ of the Black/Non Hispanic female administrators reported having no children living at home and $21(40 \%)$ of the Hispanic female administrators reported having no children living at home. Of those who reported having one child living at home, $17(32 \%)$ of them were Hispanic administrators, while only $5(10 \%)$ were Black/Non Hispanic administrators, and $8(16 \%)$ were White/Non Hispanic administrators. Fifteen $(30 \%)$ of the Black/Non Hispanic administrators and $15(28 \%)$ of the Hispanic administrators reported having two or more children living at home, while only 6 $(12 \%)$ of the White/Non Hispanic administrators reported having two or more children living at home (see Table 3 ). 
$\underline{\text { Table } 3}$

Number of Children of Females With Higher-Level Administrative Positions by Ethnicity $(\mathrm{N}=152)$

\begin{tabular}{|c|c|c|c|}
\hline & $\frac{\text { White/Non }}{\text { Hisvanic }}$ & $\frac{\text { Black/Non }}{\text { Hispanic }}$ & Hispanic \\
\hline Variable & $\underline{\%}$ & $\%$ & $\underline{N}$ \\
\hline
\end{tabular}

Number of Children Living at Home

$\begin{array}{lrrrrrr}\text { Zero } & 35 & 71.4 & 30 & 60.0 & 21 & 39.6 \\ \text { One } & 8 & 16.3 & 5 & 10.0 & 17 & 32.1 \\ \text { Tivo } & 6 & 12.2 & 15 & 30.0 & 15 & 28.3 \\ \text { Total } & 49 & 100.0 & 50 & 100.0 & 53 & 100.0\end{array}$

Note. $X^{2}(4, \underline{N}=152)=15.51, p=.004$.

Place of Birth of Administrators

There was a significant difference shown in birth places of the female administrators by ethnicity, $\mathrm{X}^{2}(2, \underline{\mathrm{N}}=144)=104.12, \mathrm{p}<.001$. ( )f the 50 Hispanic administrators who answered the question, $40(80 \%)$ were born ii Cuba and $10(20 \%)$ were born in the United States. The White/Non Hispanic administrators and the Black/Non Hispanic administrators reported $100 \%$ as being borm in the United States respectively. 
There was not a significant difference shown in the highest educational degree of the female administrators by ethnicity. Each of the three ethnic groups reported having 4 administrators with doctorate degrees $(8 \%)$. Nineteen of both the Black/Non Hispanic administrators and the Hispanic administrators reported holding specialist degrees (Black/Non Hispanic administrators $=39 \%$, Hispanic administrators $=38 \%)$. Of the White/Non Hispanic administrators, $28(60 \%)$ held masters degrees. Twenty-six (53\%) of the Black/Non Hispanic administrators reported holding masters degrees and $27(54 \%)$ of the Hispanic administrators reported holding masters degrees (see Table 4). 
Table 4

Highest Degree of Females With Higher-Level Administrative Positions, by Ethnicity $(\mathrm{N}=146)$

\begin{tabular}{|c|c|c|c|}
\hline & $\begin{array}{l}\text { White/Non } \\
\text { Hispanic }\end{array}$ & $\frac{\text { Black/Non }}{\text { Hispanic }}$ & $\underline{\text { Hispanic }}$ \\
\hline Jariable & $\underline{N} \quad \%$ & $\underline{N} \quad \%$ & $\underline{N}$ \\
\hline
\end{tabular}

Highest Educational Degree

$\begin{array}{lcccccc}\text { Masters } & 28 & 59.6 & 26 & 53.1 & 27 & 54.0 \\ \text { Specialist } & 15 & 31.9 & 19 & 38.8 & 19 & 38.0 \\ \text { Doctorate } & 4 & 8.5 & 4 & 8.2 & 4 & 8.0 \\ \text { Total } & 47 & 100.0 & 49 & 100.0 & 50 & 100.0\end{array}$

Note. $X^{2}(4, \underline{N}=146)=.59, p=.96$.

\section{Age of Job Appointment of Administrators}

There was no significant difference shown in the age of the present job appointment of the female administrators by ethnic group, $X^{2}(2, \underline{N}=151)=1.87$. $\mathrm{p}=.39$. Of those female higher-level administrators reporting being appointed to their present job at age 44 or younger, $26(53 \%)$ were White/Non Hispanic, 28 $\left(57^{\circ}{ }_{0}\right)$ were Black/Non Hispanic, and $35(66 \%)$ were Hispanic. Twenty-three $\left(47^{\circ}\right.$ o) of the White/Non Hispanic administrators were appointed to their present job position at age 45 or older, while $21(43 \%)$ of the Black Non Hispanic 
administrators and $19(34 \%)$ of the Hispanic administrators were appointed to their present positions at age 45 older.

\section{Professional Characteristics}

\section{Goal Orientation and Perception of Success of Administrators}

There was no significant difference shown in the goal orientation of the female administrators by ethnicity. When responding to the question regarding whether the present position was the ultimate occupational goal, $28(61 \%)$ of the White/Non Hispanic female administrators, 25 (50\%) of the Black/Non Hispanic administrators, and $22(42 \%)$ of the Hispanic administrators responded that it was. Eighteen (39\%) of the White/Non Hispanic administrators, $25(50 \%)$ of the Black/Non Hispanic administrators, and 31 (59\%) of the Hispanic administrators responded that their present position was not the ultimate occupational goal (see Table 5).

There was a significant difference shown in the perception of success of the female administrators by ethnicity, $p=.030$. Of the Hispanic administra:tn:s, 50 $\left(94^{\circ} \%\right)$ rated themselves as highly successful, while only $38(78 \%)$ of the White/Non Hispanic and Black/Non Hispanic administrators rated themselves as very successful (see Table 5). 


\section{$\underline{\text { Table } 5}$}

Personal Characteristics of Females With Higher-Level Administrative Positions by Ethnicity

\begin{tabular}{|c|c|}
\hline White/Non & Black/Non \\
\hline Hispanic & Hispanic \\
\hline
\end{tabular}

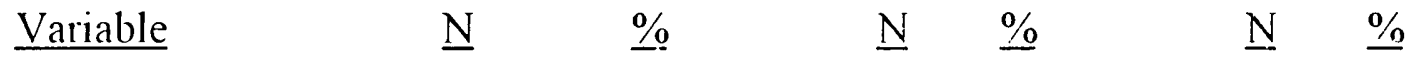

Present Position is Ultimate Occupational Goal

$\begin{array}{lcccccc}\text { Yes } & 28 & 60.9 & 25 & 50.0 & 22 & 41.5 \\ \text { No } & 18 & 39.1 & 25 & 50.0 & 31 & 58.5 \\ \text { Total } & 46 & 100.0 & 50 & 100.0 & 53 & 100.0\end{array}$

Professional Self-Rating

Very

$\begin{array}{lllllll}\text { Successful } & 38 & 77.6 & 38 & 77.6 & 50 & 94.3\end{array}$

Moderately

$\begin{array}{lllllll}\text { Successful } & 11 & 22.4 & 11 & 22.4 & 3 & 5.7\end{array}$

\begin{tabular}{ccccccc}
\cline { 2 - 6 } Total & 49 & 100.0 & 49 & 100.0 & 53 & 100.0 \\
\hline
\end{tabular}

Note. Goal: $X^{2}(2, \underline{N}=149)=3.70, p=.16$

Self Rating: $X^{2}(2, \underline{N}=151)=7.02, p=.03$ 
Perception of Barriers to Career Advancement Which Showed Significance by Ethnicity

Seventeen Likert-type items in Section III of the survey questionnaire reflected many of the barriers previously outlined in Chapter 2 - Review of Related Literature. The respondents were asked about their perceptions of the barriers perceived as hindering women in their career advancement in educational administration and to indicate on a seven-point scale (where $1=$ Not a Factor and $7=$ Serious Factor) the barriers which had or had not deterred them in their pursuit of professional career goals as administrators.

Of the 17 barriers presented on the survey questionnaire, 4 showed significance by ethnicity. The barrier, a higher level of training required in order to be competitive with male colleagues, showed the greatest significance by ethnicity, $\mathrm{p}=.003$. Black/Non Hispanic female administrators perceived the requirement of a higher level of training in order to be competitive with male colleagues as significantly more of a barrier $(\underline{m}=2.80)$ than both Hispanic female administrators $(\underline{\mathrm{m}}=1.98)$ and White/Non Hispanic female administrators $(\underline{m}=$ 1.80) (see Table 6). 
Table 6

$\underline{\text { Significant Differences for Barriers Perceived by Ethnicity }(N=147)}$

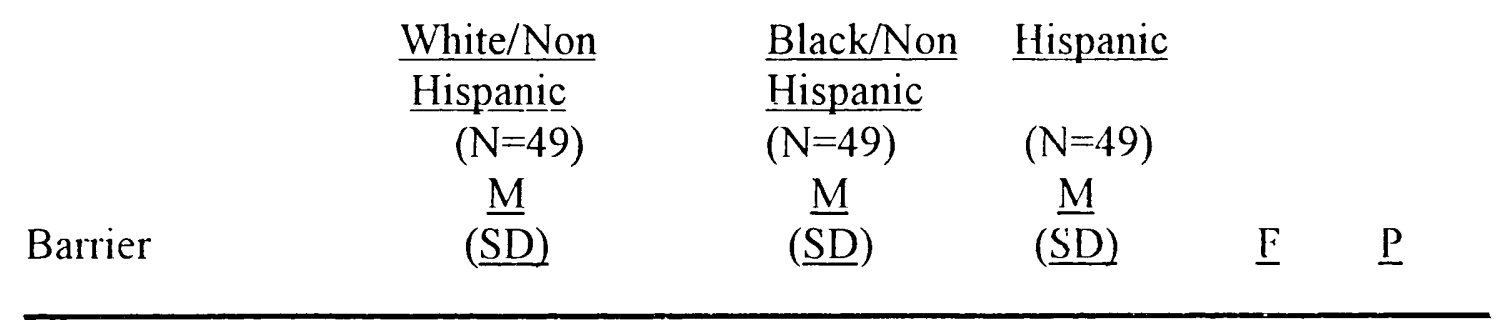

More Training

Required to be

Competitive

With Males

1.80

2.80

(1.46)

(1.74)

1.98

$6.20 \quad .003$

Exclusion

From

Informal

Network

4.55

4.78

3.57

4.63

.011

Lack of

(2.40)

(1.96)

(2.10)

Professional

Network

3.53
$(2.18)$

4.00

2.93

$3.79 \quad .025$

(2.01)

(1.80)

Conflicts

Between

Roles of

Wife/Career

2.84

(1.93)

$$
3.04
$$

(1.99)
3.77

(1.92)

Note. All tests statistically significant at $p<.05$.

$$
1=\text { Not a Factor, } 7=\text { Serious Factor }
$$


The barrier exclusion from the informal socialization process into the profession (i.e., the "Good Old Boy Network") showed significant differences by ethnicity, $\mathrm{p}=.011$. Black/Non Hispanic female administrators perceived the exclusion from the informal socialization process into the profession as a more significant barrier $(\underline{m}=4.78)$ than Hispanic female administrators $(\underline{m}=357)$ (see Table 6).

There was a significant difference shown in the barrier of a lack of a professional network (i.e., a support group to develop strategies for career adrancement, to address specific problems, to share experiences) by ethnicity, $\mathrm{p}=$ 025. Black/Non Hispanic female administrators perceived a lack of a professional network as a significantly more serious factor $(\underline{m}=4.00)$ than Hispanic female administrators $(\underline{m}=2.93)($ see Table 6$)$.

There was also a significant difference shown in the barrier conflicts between the roles of wife/mother and career woman by ethnicity, $p=.039$. Hispanic female administrators perceived the conflicts between the roles of wife/mother and career woman as significantly more of a barrier $(\underline{m}=3.77)$ than White/Non Hispanic female administrators $(\underline{m}=2.84)$ (see Table 6). 


\section{Perception of Barriers to Career Advancement Which Did Not Show Significance}

\section{by Ethnicity}

There were 13 perceived barriers to career advancement that did not show significant differences by ethnicity. Of the 13 , three showed marginal significance, $p<10$. There was a marginally significant difference by ethnicity for the barrier of the existence of "cronyism" or the "buddy system" where men refer their male associates to jobs, $\mathrm{p}=.081$. Black/Non Hispanic female administrators indicated it as a barrier $(\underline{m}=4.66)$ more significantly than White/Non Hispanic female administrators $(\underline{\mathrm{m}}=4.16)$ and Hispanic female administrators $(\underline{\mathrm{m}}=3.65)$ (see Table 7).

Experiencing differential treatment on the basis of sex during the formal application, screening, and selection processes posed a marginally significant barrier by ethnicity, $\mathrm{p}=.098$. Again, Black/Non Hispanic female administrators indicated it as a barrier $(\underline{\mathrm{m}}=3.28)$ more than Hispanic female administrators $(\underline{\mathrm{m}}=$ $2.65)$ and White/Non Hispanic female administrators $(\underline{m}=2.65)$ (see Table 7).

There was a marginally significant difference by ethnicity for having a lack of a prior opportunity to qualify for higher level administrative positions as a barrier, $\mathrm{p}=.098$. Once again, Black/Non Hispanic female administrators indicated it as a barrier $(\underline{m}=3.68)$ more than White/Non Hispanic female 
administrators $(\underline{m}=3.06)$ and Hispanic female administrators $(\underline{m}=2.89)$ (see Table 7).

\section{$\underline{\text { Table } 7}$}

Marginally Significant Differences for Barriers Perceived by Ethnicity $(\mathrm{N}=156)$

Barrier

$\frac{\text { White/Non }}{\text { Hispanic }}$
$\begin{gathered}(\mathrm{N}=49) \\ \text { M } \\ (\underline{\mathrm{SD}})\end{gathered}$

\begin{tabular}{|c|c|}
\hline Black/Non & Hispanic \\
\hline Hispanic & \\
\hline$(N=49)$ & $(N=49)$ \\
\hline$\underline{\mathrm{M}}$ & $\stackrel{M}{(\mathrm{SD})}$ \\
\hline
\end{tabular}

$\underline{F} \quad \underline{P}$

Men Refer Their

Male Associates

To Jobs
4.16

4.66

3.65

2.56

.081

(2.47)

(2.11)

(2.26)

Differential

Treatment on

The Basis of

Sex

$$
2.52
$$

3.28

(1.80)

(1.80)

2.65

$2.36 \quad .098$

Lack of

Prior

Opportunities

To Qualify

$$
\begin{gathered}
3.06 \\
(1.96)
\end{gathered}
$$

3.68

(2.13) 
The ten other perceived barriers to career advancement that did not show significant differences by ethnicity were 1) teachers, parents, and community preferences for male rather than female administrators; 2) lack of career mobility; 3) lack of role models; 4) experiencing problems in overcoming stereotypic attitudes about women's appropriate roles in society; 5) lowered aspirations because of limited opportunities for growth and advancement; 6) superior's negative attitudes about women's competency and effectiveness in administrative positions; 7) experiencing a lack of encouragement or support from family and peers; 8) lack of influential mentors; 9) having a small proportion of women in higher-level adıninistration which affects how you are perceived by and responded to by colleagues (e.g., as "tokens"); and 10) having a lack of motivation to pursue particular administrative positions because of past obstacles encountered.

\section{Ranks of Means of Perceived Barriers to Career Advancement}

The means for the perceived barriers to career advancement for White/Non Hispanic higher-level female administrators, Black/Non Hispanic higher-level female administrators, and Hispanic higher-level female administrators are ranked from serious to not a factor in Tables 8,9 , and 10. It is important to note the slightly higher overall mean values for many of the barriers for Black/Non Hispanic female administrators over the White/Non Hispanic female 
administrators and Hispanic female administrators. Also important, the most significant barrier listed for the Black/Non Hispanic females and White/Non Hispanic females is the exclusion from the informal socialization process in to the profession (i.e., the "Good Old Boy Network"). However, the most significant barrier listed for the Hispanic female administrators is the conflicts between the roles of wife/mother and career woman. That barrier is eleventh in the ranking of means for both the White/Non Hispanic females and the Black/Non Hispanic females. Another important note is the lowered ranking for all three categories of administrators for the barrier, lack of encouragement from family and peers. 
Table 8

Rank of Means With Standard Deviations for the Perceived Barriers to Career Advancement of Black/Non Hispanic Higher-Level Female Administrators Ranked from Serious Factor to Not a Factor $(N=49)$.

Variable Label

$\underline{\mathrm{SD}}$

Q25

exclusion from informal socialization

$4.78 \quad 1.96$

Q17

men refer their male associates to jobs

$4.66 \quad 2.11$

Q27

small proportion of women in administration

$4.12 \quad 2.08$

Q26

lack of influential mentors

$\begin{array}{ll}4.12 & 2.29\end{array}$

Q13

lack of professional network

$4.00 \quad 2.01$

Q15

lack of prior opportunities to qualify

3.68

2.13

Q18

lack of career mobility

$3.67 \quad 1.97$

Q14

other's preferences for male administrators

3.32

1.99

Q16

differential treatment on the basis of sex

$3.28 \quad 1.80$

Q2

problems overcoming stereotypes

$3.22 \quad 1.80$

Q19

role conflicts between wife/mom and career

$3.04 \quad 1.99$

Q23

superiors' negative attitudes about women

$\begin{array}{ll}2.88 & 1.87\end{array}$

Q20

lack of role models

$2.84 \quad 1.86$

Q29

more training required to be competitive

$2.80 \quad 1.74$

Q28

lack of motivation to pursue new positions

$2.70 \quad 1.90$

Q2

lowered aspirations

$2.54 \quad 1.82$

Q2+

lack of encouragement from family/peers

1.66

1.21

Note. $1=$ Not a Factor

$7=$ Serious Factor 
Rank of Means With Standard Deviations for the Perceived Barriers to Career Advancement of White/Non Hispanic Higher-Level Female Administrators Ranked from Serious Factor to Not a Factor $(\mathrm{N}=45)$.

$\underline{\text { Variable Label }} \underline{M} \underline{\text { SD }}$

Q25 exclusion from informal socialization

$4.55 \quad 2.40$

Q17 men refer their male associates to jobs

$4.16 \quad 2.47$

Q26 lack of influential mentors

$3.73 \quad 3.43$

Q13 lack of a professional network

$3.53 \quad 2.18$

Q27

small proportion of women in administration

3.452 .20

Q18

lack of career mobility

$3.42 \quad 2.01$

Q14

others' preferences for male administrators

$3.16 \quad 1.94$

Q21

problems overcoming stereotypes

$3.12 \quad 2.07$

Q15

lack of prior opportunities to qualify

$3.06 \quad 1.96$

Q22

lowered aspirations

$\begin{array}{ll}2.88 & 1.99\end{array}$

Q19

role conflicts between wife/mom and career

$2.84 \quad 1.93$

Q23

superiors' negative attitudes about women

$2.67 \quad 1.97$

Q16

differential treatment on the basis of sex

$2.52 \quad 1.80$

Q20

lack of role models

$\begin{array}{ll}2.51 & 1.77\end{array}$

Q28

lack of motivation to pursue new positions

$2.22 \quad 1.70$

Q24

lack of encouragement from family/peers

$1.82 \quad 1.44$

Q29

more training required to be competitive

- $1.80 \quad 1.46$

Note. $1=$ Not a Factor

$7=$ Serious Factor 
Table 10

Rank of Means With Standard Deviations for the Perceived Barriers to Career Advancement of Hispanic Higher-Level Female Administrators Ranked from Serious Factor to Not a Factor $(\mathrm{N}=52)$.

Variable Label

M $\quad \underline{\text { SD }}$

Q19 role conflicts between wife/mom and career

$3.77 \quad 1.92$

Q17

men refer their male associates to jobs

3.652 .26

Q25

exclusion from informal socialization

$3.57 \quad 2.10$

Q27

small proportion of women in administration

$3.52 \quad 2.04$

Q26

lack of influential mentors

$3.46 \quad 2.13$

Q21

problems overcoming stereotypes

3.06

1.99

Q13

lack of a professional network

$2.93 \quad 1.80$

Q18

lack of career mobility

2.93

Q15

lack of prior opportunities to qualify for positions

2.89

Q14

others' preferences for male administrators

$2.80 \quad 1.94$

Q20

lack of role models

$2.77 \quad 1.86$

Q23

superiors' negative attitudes about women

$2.70 \quad 2.02$

Q16

differential treatment on the basis of sex

$2.65 \quad 1.99$

Q22

lowered aspirations

$2.57 \quad 1.75$

Q28

lack of motivation to pursue new positions

$2.46 \quad 1.80$

Q2-

lack of encouragement from family/peers

$1.98 \quad 1.69$

Q29

more training required to be competitive

$1.98 \quad 1.34$

Note. $1=$ Not a Factor

$7=$ Serious Factor 


\section{Perceptions of the Effects of the Barriers on Career Advancement}

The respondents were asked to identify their perceptions of how the barriers listed affected them in pursuing their professional career goals. A fivepoint Likert scale, varying from $1=$ "Not at all" to $5=$ "To a Great Extent" was used to indicate the perceptions of the degree to which their career development had been affected by the perceived barriers.

On a five-point scale, five effects showed significant differences by ethnicity. The greatest significance was shown in the barrier effect, exclusion from the informal network, $\mathrm{p}<.001$. Black/Non Hispanic females perceived it as significantly more of a barrier effect $(\underline{m}=3.22)$ than both White/Non Hispanic females $(\underline{m}=2.86)$ and Hispanic females $(\underline{m}=1.78)($ see Table 11). 
Table 11

Significant Differences for the Perceived Effects of Barriers by Ethnicity $(N=$ $\underline{156)}$

\begin{tabular}{|c|c|c|c|c|c|}
\hline Effect & $\begin{array}{l}\frac{\text { White/Non }}{\text { Hispanic }} \\
\begin{array}{l}(\mathrm{N}=49) \\
\underline{\mathrm{M}} \\
(\underline{\mathrm{SD}})\end{array}\end{array}$ & $\begin{array}{c}\frac{\text { Black/Non }}{\text { Hispanic }} \\
(\mathrm{N}=49) \\
\underline{\mathrm{M}} \\
(\underline{\mathrm{SD}})\end{array}$ & $\begin{array}{c}\text { Hispanic } \\
(\mathrm{N}=49) \\
\underline{\mathrm{M}} \\
(\underline{\mathrm{DD}})\end{array}$ & $\underline{F}$ & $\underline{P}$ \\
\hline \multicolumn{6}{|l|}{$\begin{array}{l}\text { Exclusion } \\
\text { From Informal }\end{array}$} \\
\hline Network & $\begin{array}{c}2.86 \\
(1.42)\end{array}$ & $\begin{array}{c}3.22 \\
(1.59)\end{array}$ & $\begin{array}{l}1.78 \\
(1.04)\end{array}$ & 15.95 & .001 \\
\hline $\begin{array}{l}\text { Problems } \\
\text { Balancing } \\
\text { Femininity/ }\end{array}$ & & & & & \\
\hline Professionalism & $\begin{array}{l}1.43 \\
(.82)\end{array}$ & $\begin{array}{l}1.84 \\
(1.17)\end{array}$ & $\begin{array}{l}1.37 \\
(.68)\end{array}$ & 4.05 & .019 \\
\hline \multicolumn{6}{|l|}{ Interruption } \\
\hline Of Career & $\begin{array}{l}1.38 \\
(.91)\end{array}$ & $\begin{array}{l}1.46 \\
(.84)\end{array}$ & $\begin{array}{c}1.89 \\
(1.22)\end{array}$ & 3.79 & .025 \\
\hline \multicolumn{6}{|l|}{$\begin{array}{l}\text { Delayed } \\
\text { Career Due } \\
\text { To Family }\end{array}$} \\
\hline Responsibility & $\begin{array}{c}2.00 \\
(1.32)\end{array}$ & $\begin{array}{c}1.86 \\
(1.12)\end{array}$ & $\begin{array}{c}2.47 \\
(1.45)\end{array}$ & 3.11 & 048 \\
\hline
\end{tabular}

Denied Access

To Power

Groups

Note. All tests are statistically significant at $p<.05$.

$1=$ Not at All, $5=$ To a Great Extent 
The barrier effect, problems with finding a balance between feminine identity and professionalism, showed significance by ethnicity, $\mathrm{p}=.019$. Black/Non Hispanic females found it as significantly more of a barrier effect $(\underline{m}=$ 1.84) than Hispanic females $(\underline{m}=1.37)$ (see Table 11) although means are very low indicating it was not much of a barrier.

There was also a significant difference shown by ethnicity in the barrier effect, interruption of career, $\mathrm{p}=.025$. Hispanic female administrators perceived it as significantly more of a barrier effect $(\underline{m}=1.89)$ than White/Non Hispanic female administrators $(\underline{m}=1.36)($ see Table 11$)$.

The barrier effect, career was delayed due to family responsibility, showed significance by ethnicity, $\mathrm{p}=.048$. Hispanic female administrators perceived that their careers were delayed due to family responsibility $(\underline{m}=2.47)$ signiricantly more so than Black/Non Hispanic female administrators $(\underline{m}=1.86)$ (see Table 11).

The barrier effect, being denied access to power groups that make important decisions, showed significance by ethnicity, $\mathrm{p}=.050$. White/Non Hispanic females perceived that they were denied access to power groups that make important decisions as significantly more of an effect $(\underline{m}=2.78)$ than Hispanic female administrators $(\underline{m}=2.11)$. The results are shown in Table 11 .

Five of the ten perceived barrier effects did not show significant differences by ethnicity. These are 1) having to accept less attractive and less challenging 
jobs; 2) promotions into dead end positions which are not commensurate with abilities and experience; 3) aspirations and motivations thwarted because of difficulty encountered in advancing; 4) applied less frequently for available administrative positions because of obstacles encountered; and 5) limited opportunities to advance professionally due to gender bias. Means and standard deviations of these perceived barrier effects are shown in Table 12 .

Of the ten barrier effects, Black/Non Hispanic female higher-level administrators responded with higher mean responses to a greater extent than White/Non Hispanic female higher-level administrators and Hispanic female higher-level administrators six of ten times. This indicates that Black/Non Hispanic female administrators felt that these barriers effected their careers to a greater extent than White/Non Hispanic and Hispanic female administrators. 
Non-Significant Differences for the Perceived Effects of Barriers by Ethnicity ( $N$ $=\underline{156)}$

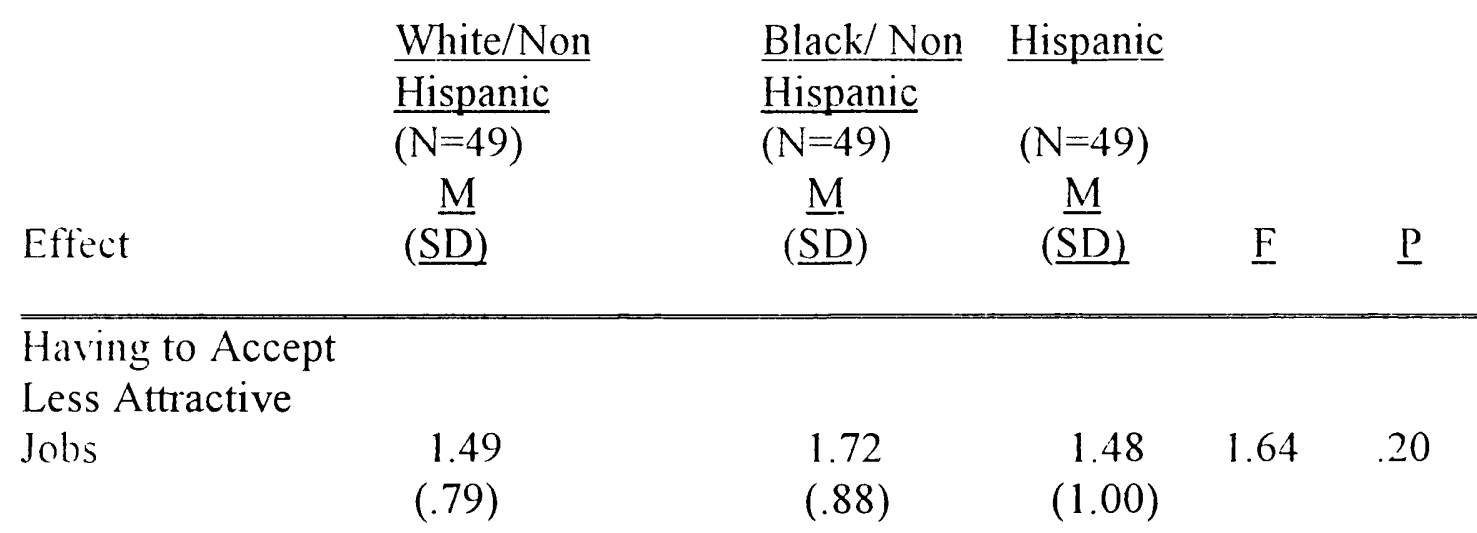

Promotions

To Dead End Positions

$\begin{array}{ccccc}1.67 & 1.92 & 1.57 & 1.33 & .27 \\ (1.16) & (1.22) & (.95) & & \end{array}$

Aspirations and

Motivations

Thwarted

$\begin{array}{ccccc}2.08 & 2.24 & 1.85 & 1.32 & .27 \\ (1.19) & (1.36) & (1.22) & & \end{array}$

Applied

Less Frequently

To Administrative

Positions

$\begin{array}{ccccc}1.76 & 1.96 & 1.68 & .78 & .46 \\ (1.23) & (1.19) & (1.19) & & \end{array}$

Limited

Opportunities

To Advance

2.00

2.04

$.40 \quad .67$

Note. All tests are not statistically significant at $p<.05$.

$1=$ Not at All, $5=$ To a Great Extent 


\section{$\underline{\text { Successful Strategies to Career Advancement }}$}

In the final section of the survey questionnaire, respondents reported their perceptions of the success rate of the strategies in accomplishing their career goals. The respondents indicated on a four-point Likert scale whether the list of strategies had been "Unsuccessful," "Somewhat Successful," "Highly Successful," or "Never Used" in advancing their specific career goals. Of the ten strategies to career advancement listed, four showed significant differences by ethnicity. The choice "Never Used" was chosen by 3 to 35 female administrators when answering nine of the ten questions with the exception of the question regarding the utilization of the "New Girl" Network. When responding to that question, 76 of the female administrators indicated that they had "Never Used" the strategy.

The strategy that showed the most significant differences by ethnicity was improving professional image, $\mathrm{p}<.001$. Forty-one $(82 \%)$ of the Hispanic female administrators indicated it as highly successful, while $30(65 \%)$ of the Black/Non Hispanic female administrators indicated it as highly successful, and $26(58 \%)$ of the White/Non Hispanic female administrators indicated it as highly successful (see Table 13).

Becoming professionally visible also showed significant differences by ethnicity, $p=.024$. Thirty-seven $(74 \%)$ of the Hispanic female administrators indicated it as a highly successful strategy, $30(64 \%)$ of the Black/Non Hispanic 
females indicated it as a highly successful strategy, and 24 (51\%) of the White/Non Hispanic females indicated it as a highly successful strategy (see Table 13). 
$\underline{\text { Table } 13}$

Significant Tests of Percentages of Success for Strategies by Ethnicity

\begin{tabular}{|c|c|c|c|c|c|c|}
\hline \multirow[b]{2}{*}{ Strategy } & \multicolumn{2}{|c|}{$\frac{\text { White/Non }}{\text { Hispanic }}$} & \multicolumn{2}{|c|}{$\frac{\text { Black Non }}{\text { Hispanic }}$} & \multicolumn{2}{|c|}{ Hispanic } \\
\hline & $\underline{N}$ & \% & $\underline{N}$ & $\underline{\%}$ & $\underline{N}$ & $\%$ \\
\hline $\begin{array}{l}\text { Improving } \\
\text { Professional } \\
\text { Image }\end{array}$ & & & & & & \\
\hline Unsuccessful & 0 & 0.0 & 6 & 13.0 & 0 & 0.0 \\
\hline $\begin{array}{l}\text { Somewhat } \\
\text { Successful }\end{array}$ & 19 & 42.2 & 10 & 21.7 & 9 & 18.0 \\
\hline $\begin{array}{l}\text { Highly } \\
\text { Successful }\end{array}$ & $\underline{26}$ & 57.8 & 30 & 65.2 & 41 & 82.0 \\
\hline Total & 45 & 100.0 & 46 & 100.0 & 50 & 100.0 \\
\hline
\end{tabular}

Becoming

Professionally

Visible

$\begin{array}{lllllll}\text { Lnsuccessful } & 1 & 2.1 & 4 & 8.5 & 0 & 0.0\end{array}$

Somewhat

Successful

$22 \quad 46.8$

$13 \quad 27.7$

$13 \quad 26.0$

Highly

Successful

$\underline{24}$

51.1

$30 \quad 63.8$

$37 \quad 74.0$

Total

$47 \quad 100.0$

$47 \quad 100.0$

$50 \quad 100.0$

Note. Image: $\mathrm{X}^{2}(4, \underline{N}=141)=20.38, p<.001$

Visible: $X^{2}(4 . \underline{N}=144)=11.26 . p=.02$ 
Seeking advanced training and certification showed significant differences by ethnicity as a strategy utilized in accomplishing career goals, $p=.027$. Of the Hispanic female administrators, $44(85 \%)$ indicated it as highly successful, while $37(76 \%)$ of the Black/Non Hispanic female administrators and $31(69 \%)$ of the White/Non Hispanic female administrators indicated it as a highly successful strategy (see Table 14).

The strategy, being more assertive in pursuing career goals, showed significant differences by ethnicity, $\mathrm{p}=.044$. Thirty-two $(62 \%)$ of the Hispanic female administrators indicated it as a highly successful strategy, $24(52 \%)$ of the Black/Non Hispanic females indicated it as a highly successful strategy, and 21 $(47 \%)$ of the White/Non Hispanic females indicated it as a highly successful strategy (see Table 14).

Two strategies showed marginally significant differences by ethnicity, $p<$ 10. Attending seminars and administrative training workshops to improve professional and personal skills showed marginally significant differences by ethnicity, $p=.07$. Of the Hispanic female administrators, $39(75 \%)$ indicated it as a highly successful strategy while $29(59 \%)$ of the Black/Non Hispanic fernale administrators and $25(54 \%)$ of the White/Non Hispanic female administrators indicated it as a highly successful strategy (see Table 15). 
There was a marginally significant difference by ethnicity for enlisting influential sponsors, $\mathrm{p}=.08$. Twenty $(50 \%)$ of the Hispanic female administrators and $16(50 \%)$ of the White/Non Hispanic female administrators indicated it as a highly successful strategy while $17(41 \%)$ of the Black/Non Hispanic female administrators indicated it as a highly successful strategy (see Table 15). 
Table 14

Significant Tests by Ethnicity of Percentages of Success for Strategies

$\begin{array}{cccc}\frac{\text { White/Non }}{\text { Hispanic }} & \frac{\text { Black/Non }}{\text { Hispanic }} & \text { Hispanic } \\ \text { Strategy } & \underline{N} \quad \underline{N} \underline{\text { N }} & \underline{N}\end{array}$

Seeking Advanced

Training

$\begin{array}{lllllll}\text { Unsuccessful } & 1 & 2.2 & 5 & 10.2 & 0 & 0.0\end{array}$

Somewhat

Successful

$13 \quad 28.9$

$7 \quad 14.3$

$8 \quad 15.4$

Highly

Successful

\begin{tabular}{llllll}
31 & 68.9 & 37 & 75.5 & 44 & 84.6 \\
\hline
\end{tabular}

Total

$45 \quad 100.0$

$49 \quad 100.0$

$52 \quad 100.0$

Being Assertive

In Pursuing

Career Goals

Unsuccessful

2

4.4

$6 \quad 13.0$

$\begin{array}{ll}0 & 0.0\end{array}$

Somewhat

Successful

22

48.9

$\begin{array}{ll}16 & 34.8\end{array}$

$20 \quad 38.5$

Highly

Successful

$\underline{21}$

46.7

$24 \quad 52.2$

$32 \quad 61.5$

Total

45

100.0

$46 \quad 100.0$

$\begin{array}{ll}52 & 100.0\end{array}$

Note. Training: $X^{2}(4, \underline{N}=146)=10.96, p=.03$

Assertive: $X^{2}(4, \underline{N}=143)=9.81, p=.04$ 


\section{Table 15}

Marginally Significant Tests of Percentages of Success for Strategies by Ethnicity

\begin{tabular}{|c|c|c|c|c|}
\hline \multirow[b]{3}{*}{ Strategy } & \multirow{2}{*}{$\frac{\text { White/Non }}{\text { Hispanic }}$} & Black/Non & \multicolumn{2}{|c|}{ Hispanic } \\
\hline & & Hispanic & & \\
\hline & $N \quad \%$ & $N \quad \%$ & $\underline{N}$ & $\%$ \\
\hline
\end{tabular}

Attending

Seminars/Workshops

Unsuccessful

6

13.0

$5 \quad 10.2$

$0 \quad 0.0$

Somewhat

Successful

$15 \quad 32.6$

$15 \quad 30.6$

$13 \quad 25.0$

Highly

Successful

25

54.3

$29 \quad 59.2$

$39 \quad 75.0$

Total

$46 \quad 100.0$

$49 \quad$ i 00.0

$52 \quad 100.0$

Enlisting

Influential

Sponsors

Unsuccessful

2

6.3

7

16.7

$\begin{array}{ll}0 & 0.0\end{array}$

Somewhat

Successful

14

43.8

18

42.9

$21 \quad 50.0$

Highly

Successful

16

50.0

$17 \quad 40.5$

$20 \quad 50.0$

Total

$32 \quad 100.0$

$42 \quad 100.0$

$42 \quad 100.0$

Note. Seminars: $\mathrm{X}^{2}(4, \underline{N}=147)=8.65 . p=.07$

Sponsors: $X^{2}(4, \underline{N}=116)=8.44 . p=.08$ 
Four strategies for success in accomplishing career goals did not show significant differences by ethnicity. They were 1) setting career goals and formulating a plan of action; 2) developing/utilizing "New Girl" Networks; 3) Obtaining support from family and/or peers; and 4) learning to cope with multiple roles - wife/mother/professional (see Tables 16 and 17). 
$\underline{\text { Table } 16}$

Non-Significant Tests of Percentages of Success for Strategies by Ethnicity

\begin{tabular}{|c|c|c|c|}
\hline & White/Non & Black/Non & Hispanic \\
\hline & $\underline{\text { Hispanic }}$ & Hispanic & \\
\hline Strategy & $\underline{N} \quad \underline{\%}$ & $\underline{N} \quad \underline{\%}$ & $\underline{N}$ \\
\hline
\end{tabular}

Setting Career

Goals

$\begin{array}{lllllll}\text { Unsuccessful } & 0 & 0.0 & 3 & 6.1 & 0 & 0.0\end{array}$

Somewhat

Successful

$16 \quad 356$

$16 \quad 32.7$

$15 \quad 29.4$

Highly

Successful

29

64.4

$30 \quad 61.2$

$36 \quad 70.6$

Total

$45 \quad 100.0$

$49 \quad 100.0$

$51 \quad 100.0$

New Girl

Network

$\begin{array}{lllllll}\text { Unsuccessful } & 3 & 13.6 & 9 & 34.6 & 3 & 10.7\end{array}$

Somewhat

Successful

$13 \quad 59.1$

$11 \quad 42.3$

$18 \quad 64.3$

Highly

Successful

\begin{tabular}{llllll}
6 & 27.3 & 6 & 23.1 & 7 & 25.0 \\
\hline 22 & 100.0 & 26 & 100.0 & 28 & 100.0
\end{tabular}

Total

$22 \quad 100.0$

$26 \quad 100.0$

(

Note. Goals: $X^{2}(4, \underline{N}=145)=6.50, p=.16$

Network: $X^{2}(4, \underline{N}=76)=5.83, p^{--.21}$ 
Table 17

Tests of Non-Significant Percentages of Success for Strategies by Ethnicity

\begin{tabular}{|c|c|c|c|}
\hline & White/Non & Black/Non & Hispanic \\
\hline erry & $\frac{\text { Hispanic }}{\mathrm{N}}$ & $\frac{\text { Hispanic }}{\mathrm{N}}$ & 0 \\
\hline
\end{tabular}

Obtaining Support

From Family/Peers

$\begin{array}{lllllll}\text { Unsuccessful } & 1 & 2.2 & 1 & 2.1 & & 1\end{array}$

Somewhat

Successful

13

28.3

$5 \quad 10.6$

$10 \quad 18.9$

Highly

Successful

$\underline{32}$

69.6

$41 \quad 87.2$

$42 \quad 79.2$

Total

$46 \quad 100.0$

$47 \quad 100.0$

$53 \quad 100.0$

Coping With

Multiple Roles

Unsuccessful

12.6

$1 \quad 2.6$

$0 \quad 0.0$

Somewhat

Successful

13

33.3

$11 \quad 28.2$

$12 \quad 2 \Sigma 0$

Highly

Successful

$25 \quad 64.1$

27

69.2

$36 \quad 75.0$

Total

$39 \quad 100.0$

$39 \quad 100.0$

$48 \quad 100.0$

Note. Goals: $X^{2}(4, \underline{N}=146)=4.70, p=.32$

Roles: $X^{2}(4, \underline{N}=126)=2.13, p=.71$ 
It is important to note that of the ten strategy questions, the percentage of Hispanic female administrators who chose highly successful was the highest in six strategy questions (see Tables 13 - 17). Also, on seven of the strategy questions, none of the Hispanic female administrators utilized the unsuccessful category as a response (see Tables $13-17$ ).

\section{Voluntary Narrative Section}

At the end of the questionnaire, the respondents were asked to voluntarily utilize the lines provided to comment of either the perceived barriers. the effects of the barriers, and/or the strategies utilized to overcome the barriers as a female administrator in the public school system. Of the 156 respondents, only 44 chose to respond on the voluntary comment section. The remaining 112 respondents left the voluntary narrative portion of the questionnaire blank.

The responses ranged from those who agree that discrimination on the basis of gender does occur within the administrative ranks of the school system 'see Tables 18 and 19), to those who felt other issues were more important to eight respondents who had never experienced any difficulties. One respondent vrote. "The barrier presenting the most obstacles to me has been the "boys club" multality of the upper administrators within the Miami-Dade County Schools. Only the chosen "guys" get the jobs, and the top jobs go by direct appointment.... 
not the interview process." Those who responded in kind tended to agree. Another administrator responded that “....It's very hard for a female to break into the close knit "club" at the Superintendent's level - the level where the decision makers are. Those are the "macho men," that's the group to aspire to break into..." Summing up her feelings, an administrator wrote, "The "old boy" network is alive and strong..." 
Voluntary Narrative Responses of Respondents on the Subject of the Difficulties of Females in Advancement as it Relates to Males/Sexism

Respondent $\quad$ Response on the Sexism Faced by Female Administrators

7

174

185

186

196

211
"Cronyism" isn't only about gender. It's impact is profound and gender, I believe, is a part of it.

Most of the female administrators are in the middle school -. not the senior high. In addition, our districts' six regions only have one female superintendent. It is still a male's world.

If you joined "the guys" you are branded as she's having "extra curricular" activities to get ahead. Yet there are no other females to relate to.

It is still difficult to have access to higher level decisions. Often they take place in the male bathroom. I feel women have a long way to go.

As a female in a heavy industrial male dominated environment, the staff who report to me have difficulty accepting a female without a similar background as theirs directing what they do.

The barrier presenting the most obstacles to me has been the "boys club" mentality of upper administrators within Miami-Dade County Schools. Only the chosen "guys" get the jobs, and the top jobs go by direct appointment.... not the interview process.

The "old boy" network is alive and strong. If you don't have a powerful mentor, your career is at a plateau. Merit will only get you so far. 
Voluntary Narrative Responses of Respondents on the Subject of Discrimination in Advancement as it Relates to Males/Sexism

\section{Respondent $\quad$ Response on the Sexism Faced by Female Administrators}

212

Within the public school system, there is a definitive lack of women in top roles. This is a result of many males of these levels whom I believe are afraid to allow women into the ranks - especially competent, strong, brighit. women who speak their minds as opposed to learn their place.

238

It's embarrassing to only have one deputy superintendent in that is female in our system - what kind of role model is that! How involved are females at the top decision level? It's very hard for a female to break into the close knit "club" at the Superintendent's level - the level where the decision makers are. Those are the "macho men," that's the group to aspire to break into and then mentor other females to join in.

259

The lack of women in positions that leads to advancement will continue to cause a low number of women in top level positions. Until more women are in decision-making roles. this issue will continue to persist.

Table 20 gives the narrative statements of those who felt that females not supporting females is the greatest obstacle faced by higher-level temale administrators. One female administrator wrote, "Females are sometimes their own worst enemies..." In agreement, another female administrator volunteered. "Often. women are more of a barrier to other women...." 
Voluntary Narrative Responses of Respondents on the Subject of Females Assisting Other Females in the Advancement Process

Respondent $\quad$ Response on Females Assisting Other Females

$90 \quad$ Females are sometimes their own worst enemies. In their quest for success, they are not willing to share their knowledge. In addition, rather than admit that they don't know a policy or procedure, they become defensive and aggressive toward other females.

185

Women do not necessarily support other women. Men are more supportive of other men.

259 Often, women are more of a barrier to other women getting advancement.

A select group of eight higher-level female administrators felt that it was important to note the racial/ethnic discrimination that occurs within the school system (see Table 21). One administrator responded, "I have encountered more negativism being perceived as a Hispanic token." Another administrator vrote, "Once you understand they don't desire intelligent, thoughtful, competent people especially Anglo females - then you're okay!" Yet another administrator stated that. "Black females have even more barriers, based on the number of Black females in top administrative positions." 
Voluntary Narrative Responses of Respondents on the Subject of Racial/Ethnic Barriers Facing Female Administrators

Respondent $\quad$ Response on Racial/Ethnic Barriers Facing Females

Once you understand they don't desire intelligent, thoughtful, competent people - especially Anglo females - then you're okay!

Minority applicants usually start at the more challenging schools. Whereas all others have the full range of available positions accessible to non-Black applicants.

The biggest barriers to my becoming principal were my ethnicity and lack of visibility to those who make decisions.

Your data (questions) did not address the influence of race/ ethnicity in decisions regarding promotions.

As a Hispanic female administrator, I feel that women do not get the opportunities to rise as future superintendents. Anglo men and women are often promoted and recognized by professional organizations while Hispanics are not.

The ethnic/cultural barrier is a greater obstacle now than gender. Gender is not the greatest concern verbalized by female administrators now.

I have encountered more negativism being perceived as a "Hispanic token."

Black females have even more barriers, again based on the Number of Black females in top administrative positions. The effects of these perceived barriers is reflected in the limited number of Black females filling top level administrative positions. 
Several of the higher-level female administrators who responded to the voluntary narrative section of the questionnaire felt that other barriers were the cause of the limited success of females in the upper administrative ranks (see Tables 22 and 23). Some of the areas cited were, age, combining the roles of administrator and housewife, politics, the manner in which administrators are promoted in the school system (direct appointments), and others. Three administrators stated that politics proved as a barrier for them. One wrote, "Politics at the district level is the biggest hurdle we face!" One administrator responded that there were three barriers that existed; ethnicity, nepotism, and lack of positions. Yet another administrator wrote, "The major barrier I have faced is my inability to hide my feelings and ideas. My advancement has been thwarted by my inability to learn and play the game. Other administrators have been able to criticize me because of my honesty, openness, and my strong commitment. I should have learned, but I guess going higher didn't mean enough. No regrets!" 
Voluntary Narrative Responses of Respondents on the Subject of Other Barriers Encountered by Female Administrators

Respondent $\quad$ Response on Other Barriers Facing Female Administrators

22

97

171

206

207

225

247
The major barrier 1 have faced is my inability to hide my feelings and ideas My advancement has been thwarted by my inability to learn and play the game.

The age at which one is appointed, in my opinion, depends on how early and how vigorously one pursues one's career.

As an administrator and a housewife at the same time, I find that $I$ do not have time for ME........ and that is Not GOOD.

The primary gate for promotion is through a personal friend on a total political arena.

Politics at the district level is the biggest hurdle we face!

My area within the school system is very specialized. My superiors always must be taught our area and thus really cannot assist in the technical areas but may be supportive or non-supportive in their lack of understanding.

The accounting degree limits the area in which I can advance; it was not a gender problem.

It is difficult to achieve goals when direct appointments are made. It is extremely important to be visible, active in activities that the "guys" support, and seek the support and advice of those in higher positions.

Politics in the educational arena needs to be addressed as it relates to barriers to career advancement for women. 
Table 23

Voluntary Narrative Responses of Respondents Regarding Other Barriers Met by Female Administrators

Respondent $\quad \underline{\text { Response on Other Barriers Facing Female Administrators }}$

248

Barriers: 1) Ethnically selecting candidates because of political reasons; 2) Nepotism - increased dramatically when Hispanics were included in upper-management;

3) Not enough positions for eligible candidates.

252

I believe that a woman who is very capable needs to have the opportunity to prove herself within powerful groups.

Several higher-level female administrators felt it important to note that they had not experienced any barriers as higher-level female administrators (see Table 24). One respondent stated, "I have never encountered most of the things you have mentioned here. Maybe I was just lucky." Yet another administrator wrote, "The "Good Old Boy Network" is alive and well, but many of the "good boys" promote women. They know sometimes the best man for a job is a woman." 
Table 24

Voluntary Narrative Responses of Respondents Who Do Not Experience Barriers

Respondent Response of Those Who Do Not Experience Barriers

23

I have never personally felt any real or perceived barriers to my professional goals.

24

Except for the very top level of administration in the downtown office, I don't feel women encounter barriers to professional advancement.

53

Although I personally did not meet many barriers, I do believe they exist to some degree in the school system.

It has not been a "battle" with "outside forces" because I am focused and know what it takes to do the job effectively.

I have never encountered most of the things you have mentioned here. Maybe I was just lucky.

I do not feel that I have been inhibited in my career by being female. Many of the choices I have made have been so that my family would not be hurt by my job choices.

180

Barriers and lack of women in administration was a much greater obstacle in the 1970's and the 1980's than in the 1990's.

I have been mentored by successful women and men. Frankly. I have not felt excluded from any opportunity to advance because I am female.

The "Good C!d Boy Network" is alive and well. but many of the "good boys" promote women. They know sometimes the best man for a job is a woman. 
Finally, a few of the respondents of the voluntary narrative portion of the questionnaire felt it important to note the strategies they have utilized which have proven successful. The responses were:

The strategies utilized have been very helpful such as: networking setting goals, attending many, many seminars, and improving professional image.

The most important strategy to be utilized will always be to approach every challenge or barrier with a positive attitude. Show the world that you are "ready." Be very persistent, no matter what.

Keeping faith in God helps me to continue to push on in spite of the obstacles.

I feel that my most successful strategy has been to do the very best I can in the position I hold; and to acquire all the knowledge and training that is offered to prepare myself to advance in the career ladder. Also, maintaining high expectations for self in all endeavors. 


\section{Chapter Five - Summary, Discussion, Conclusions, and Recommendations}

\section{Summary}

The primary objectives of this study were to a) examine any distinctions among African American, Hispanic, and Anglo female public school higher-level administrators with respect to the barriers they perceive as hindering their climb "up the ladder," b) analyze the perceived effects of the barriers utilized by African American, Hispanic, and Anglo administrators in overcoming the obstacles seen as hindering their ascension in the public school system. and c) explore the strategies utilized by Anglo, Hispanic, and African American administrators in overcoming the barriers they perceive as hindering their advancement,

The study also gathered data on the personal and professional characteristics of the respondents in order to provide a composite picture of the administrators. These data were further analyzed to determine if there were any significant differences between African American female higher-level administrators, Anglo female higher-level administrators, and/or Hispanic female higher-level administrators in respect to the demographic data gathered.

The method of data collection was a survey questionnaire consisting of 49 items and a section for voluntary narrative responses. The pcpulation for the study was defined as full-time female administrators employed either as principals. 
directors, region, assistant, associate, or deputy superintendents in Miami-Dade County Public Schools as of November 1998. Of the 260 female administrators identified in the specified positions, 19 returned surveys that were either unmarked or completed by an assistant principal in place of the principal. Of the 175 surveys returned, 156 were valid for analysis. This yielded a total return rate was $67.31 \%$ for all questionnaires. Of those who returned usable questionnaires for the study, 49 were Anglo, 50 were African American, 54 were Hispanic, two were Multiracial, and one identified herself as "other." The same population consisted of 104 elementary school principals, 14 middle school principals, three senior high school principals, 15 directors, three assistant superintendents, one deputy superintendent, and 16 other non-schuol site higher-level administrators. The findings were based on the comprehensive information of all questionnaires received from these respondents.

The study data were analyzed in consideration of each of the research objectives and questions utilizing various frequency counts and percentages, crosstabulations, analysis of variance (ANOVAs), and post-hoc comparisons (Tukey's). 


\section{Discussion of Findings and Conclusions}

McGrath (1992) asserted that the top three administrative posts in public school education (superintendent, assistant superintendent, and high school principal) are overwhelmingly filled by males despite a growing body of research discerning the outstanding potential of women in all administrative positions. This study supports those findings. Of the respondents to the survey, 67\% were elementary school principals. Only $2 \%$ were senior high school principals, and only $3 \%$ were either assistant superintendents or deputy superintendents. Data suggests that the Miami-Dade County Public School system is plagued by the typical characteristic held by other school systems in the country: men dominate the top administrative positions. As Tyack and Stober stated in 1981, when hired as principals, women typically work in primary schools and supervise mainly women. This hierarchy of gender in the public school system has continued to exist in schools today. There is a persistent absence of women from the highest and most powerful administrative positions in public education (Morie \& Wilson, 1996).

Previous research studies surveying women administrators in public schools have compiled data on the personal characteristics and professional attributes of these women leaders (Bagentos, 1987). Female principals have been described as usually Anglo, Protestant, more often married than not, usually 
having children, are often the firstborn or the only child, and are from two-parent homes (Edgin, 1987; Shakeshaft, 1987; Sulowski, 1988). Schuster and Foote (1990) found that nearly $36 \%$ of the women in their study were over 46 when they got the job. Some of the previously cited research was supported by this study, while others were not. For example, the research citing the barriers experienced by African American females proved to be substantiated (Howard-Vital \& Morgan, 1993; Carter, Pearson \& Shavlik, 1988; Gill \& Showell, 1991). However, the limited research presented on the powerlessness of Hispanic female administrators (Regules, 1997; Gorena, 1996) was not confirmed by this study.

Concerning the personal characteristics of the 156 female higher-level administrators in this study, the data from this research does support the image of the married administrator. Sixty-two percent of the respondents were married, while $15 \%$ were single and $20 \%$ were divorced. However, $57 \%$ of the respondents had no children living at home. The reason for the married administrator without any children lies in the age range of the respondents. An overwhelming $75 \%$ of the respondents were 45 years of age or older, therefore, their children are adults and no longer living at home. The prototypical female higher-level admirisirator, according to the data from this study, is one who is 45 years of age or older, born in the United States. married, having no children living at home, hold:ng a master's degree, and employed as an elementary school principal. Also. this 
typical female higher level administrator was appointed to her present position at age 40 or above. The data revealed that $66 \%$ of the respondents were appointed to their present administrative positions between the ages of 40 and 54 years of age.

The ethnic classifications were evenly distributed between Anglo (32\%), African American (33\%), and Hispanic (35\%). Therefore, the prototypical female higher-level administrator in Miami-Dade County Public Schools could belong to any of the three ethnic groups.

When analyzing the demographic data by ethnicity, the primary standout was the marital status. A majority of the Hispanic females $(76 \%)$ and a majority of the Anglo females (68\%) were married. African American females reported being divorced at a higher level (38\%) than the other ethnic groups and with only $46^{\circ}$ o being married. This factor may play an important role when analyzing the barriers each group cited as hindering their careers.

A further significant demographic fact is the number of children living at home with the administrators. A majority of the Anglo female administrators $\left(71^{\circ} \%\right)$ and a majority of the African American female administrators $(60 \%)$ had no children living at home. However, with the Hispanic female administrators, $60 \%$ had one or more children living at home. This fact, coupled with the majority of the Hispanic female administrators being married, details how important the role of the family plays in the barriers perceived as hindering the career and the 
strategies utilized to overcome the barriers with the Hispanic females. In fact, the barrier, conflicts between the roles of wife/mother and career woman, showed a significant difference by ethnicity. The Hispanic female administrators perceived it as more of a barrier than Anglo female administrators did. Also, Hispanic female administrators perceived that their careers were delayed due to family responsibility more than African American female administrators did. The interruption of career as a barrier effect also showed a significant difference by ethnicity. Hispanic female administrators reported that their careers were interrupted more than Anglo female administrators. This is most likely due to the Hispanic female administrators interrupting their careers to have ramilies. One Hispanic female administrator wrote, "I feel that I have not been recognized professionally because I dedicate nights and weekends to my family." Another Hispanic female administrator stated, "I do not seek job choices large distances from my home, in order to avoid drive time that would take away from either my family or work."

Along with being more probable to have a family, Hispanic female administrators also appeared to possess more confidence in their careers. An overwhelming $94 \%$ of the Hispanic female administrators rated themselves professionally as being very successful. Acquiring and maintaining the ability to cope with a successful career while maintaining a rich family life must contribute 
to the percentage of Hispanic female administrators rating themselves professionally as very successful. With the Anglo and African American female administrators, only $78 \%$ rated themselves professionally as very successful. As stated in the voluntary narrative portion of the questionnaire, one Anglo female stated, "It is difficult to achieve goals when direct appointments are made." While an African American female administrator felt that, ".....competency, integrity, loyalty and leadership are not components recognized for higher achievement in this school district."

Significant differences by ethnicity were found in four areas identified as sirategies utilized to overcome perceived barriers. Hispanic higher-level female administrators were more likely to 1) seek advanced training (84\%); 2) become assertive in pursuing career goals $(62 \%) ; 3)$ become professionally visible $(74 \%)$; and 4) improve their professional image $(82 \%)$. In fact, Hispanic female administrators rated themselves more highly successful when utilizing strategies to overcome stated barriers when answering seven of the ten questions on strategies as compared to Anglo female administrators and African American female administrators. Hispanic female administrators in Miami-Dade County Public Schools perceive themselves as being successful in achieving what Anglo and African American female administrators are still finding troublesome: assertively utilizing available resources to enhance their careers. The success perceived by 
Hispanic female administrators in utilizing strategies to overcome barriers to career advancement should be shared with administrators of other ethnic groups. As stated by Blum (1990), such mentoring and networking could serve to provide support, encouragement, feedback, and insight.

The African American female administrators showed a significant difference as compared to Anglo with the number of years teaching prior to being appointed as an administrator. They had a greater number of years as a teacher $(\underline{m}=15.13)$. This indicates that African American female administrators have more instructional experience. It also correlates with the African American females' perception of barriers hindering their career advancement as it relates to initial placement into an administrative position.

The African American female administrators perceived the lack of a professional network as more of a barrier to their career advancement than Hispanic female administrators did. Correlating with that fact, more African American female administrators also felt they were excluded from the informal socialization process into the profession (i.e., the "Good Old Boy Network") than Hispanic female administrators. Lastly, African American female adminstrators perceived that they needed more training in order to be competitive with other administrators $(\underline{m}=2.80)$ more than Anglo $(\underline{m}=1.80)$ and Hispanic $(\underline{m}=1.98)$ female administrators did. In fact, of the 17 barriers listed on the questionnaire. 
African American female administrators answered with a higher mean score on 14 of the barriers indicating that they considered the barriers as more serious factors in career advancement.

An African American female respondent wrote the following in the voluntary narrative portion of the questionnaire, "Black females have even more barriers, based on the number of Black females in top adminstrative positions The effects of the perceived barriers is reflected in the limited number of Black females filling top level adminstrative positions." This correlates with previous research by Howard-Vital and Morgan (1993). They state that the African American woman is still perceived by many to be the least powerful in society and in most organizations. Carter, Pearson and Shavlik (1988) stated that African American women despite their numbers in the educational community, are the "most isolated, underused and consequently demorilized segment of the academic community." An African American female administrator volunteered this statement in the voluntary narrative section of the questionnaire, "It is my opinion that competency, integrity, loyality and leadership are not components recognized for higher achievement in this school district." Yet another African American female adminstrator stated, "Minority applicants usually start at the more challenging schools, whereas, all others have the full range of available positions that are only accessable to non-Black applicants." 
The fact that the African American female administrators in this study felt that they were excluded from the informal socialization process more than the other ethnic groups supports the theory of isolation cited earlier. The exclusion from informal socialization was also documented by Gill and Showell (1991). Their findings showed that many African American females believed that the politics, friendships and retwork systems outweighed the qualifications of education and experience. The fact that African American females considered the barriers to career advancement listed on the questionnaire as more serious factors, supports Fontaine and Greenlee's (1993) statement that African American women felt they had to outperform majority group counterparts. Research conducted by Jones (1993) further supports the findings of this study. She found that African American female administrators often experience social and professional isolation, often leading to feelings of lonliness, hence the significance of the previously stated barrier that African American females felt the lack of a social network as more of a hindrance than Anglo females or Hispanic females. It is up to those African African American female administrators who feel socially and professionally isolated to become aggressive in their career goals while providing a support system for one another. The support system is a must considering that many times shared success is more gratifying than individuaiized accomplishments. 
African American females also showed a significant difference from Hispanic and Anglo females when answering the questions on the effects of the barriers to career advancement. They felt that they were excluded from informal networks more than Anglo or Hispanic female adminstrators. In fact, this barrier effect showed the largest significant difference among groups than any of the questions on the survey. Again, this supports the previously cited research. It is imperative for African American female administrators to form a "New Girl Network" so that the isolation and exclusion will not hinder their career development. This is a strategy in which 79 of the respondents reported that they had never utilized it.

When answering the question regarding problems finding a balance between feminine identity and professionalism as a barrier effect, African American female administrators felt that it was more of a difficulty than Hispanic female administrators. This correlates with the Hispanic females' success with strategies in overcoming barriers such as this one.

The Anglo female administrators did not score significantly higher on: any of the barrier questions to career advancement as compared to African Anierican female adminstrators and Hispanic female adminstrators. In fact. of the eight respondents who wrote in the voluntary narrative portion that they had not experienced any barriers to their career advancement, six were Anglo. An 
example is an Anglo female administrator who wrote, "I believe my particular survey will not help you much. I have never encountered most of the things you have mentioned here. Maybe I was just lucky."

The only area in which Anglo female adminstrators showed a significant difference from African American and Hispanic female administraturs was in section regarding the perceived effects of the barriers. Anglo female administrators perceived that they were denied access to power groups that make important decisions more than Hispanic female administrators when considering it as a perceived barrier effect. This correlates with much of the research on the exclusion of females in general from top adminstrative positons (Morie \& Wilson, 1996; Gupton and Slick, 1995; Whitaker \& Lane, 1990; and Scandura, 1990). Although Anglo female administrators in this study have not experienced the barriers to the extent that African American and Hispanic female adminsitrators. there is still a glass ceiling as to the level in which they are allowed to reach. One Anglo female administrator wrote in the voluntary narrative portion of the questionnaire, "Within the public school system, there is a definitive lack of women in top roles. This is a result of many males at these levels whom I helieve are afraid to allow women into the ranks - expecially competent, strong. bright women who speak their minds, as opposed to learn their place." Another Anglo female adminstrator stated, "The old-boy network is alive and strong." 
An area of concern voiced by a few Anglo female higher-level administrators is the ethnicity issue. As written in the voluntary narrative portion of the questionnaire, an Anglo female adminstrator wrote, "The ethnic/cultural barrier is a greater obstacle now than gender. Gender is not the greatest concern verablized by female adminstrators now." A few of the other narrative responses from Anglo female higher-level adminstrators who view ethnicity as a concern are detailed below:

The biggest barriers to my becoming principal were my ethnicity and lack of visibility to those who make decisions.

Once you understand they don't desire intelligent, thoughtful, competent people - especially Anglo females - then you're okay.

Your data (questions) did not address........ the influence of race/ethnicity in decisions, re: promotions.

\section{Conclusions}

The data revealed several poignant facts. Hispanic female higher-level administrators who returned the questionnaire were more likely to be married and have children as compared to Angio and African American female administrators. Hispanic females also rated themselves higher professionally. More African American females who returned the questionnaire reported being divorced than the other ethnicities. 
When addressing the barriers to career success, four barriers proved to be significant. The Hispanic females felt that conflicts between the roles of wife/mother and career woman was a greater barrier than Anglo females. The African American females considered the following as greater barriers than Hispanic females: lack of a professional network and exciusion from informal network. African American females perceived that more training required to be competitive with males, as a barrier more than Hispanic and Anglo female administrators. African American females had a higher mean score (more serious) on 14 of the 17 barriers to career success than the other ethnic groups. The increased perceived barriers facing African American females in their advancement requires immediate action. The time has come to discontinue documenting the problems and begin highlighting solutions. African American females must be recognized for their talents as individuals and given opportunities by public school systems to prove their worth. Simultaneously, African American females should begin to utilize what has been successful for others: mentoring. networking, sharing, and supporting one another so that the perceptions of barriers are minimized and the opportunities for success are maximized.

The data focusing on the perceived effects of the barriers revealed several salient points. Hispanic female administrators felt more that their careers were delayed due to family responsibility as compared to African American females. 
They also felt that their careers were interrupted more than Anglo female administrators. African American females indicated that they were excluded from informal networks and had more problems balancing femininity and professionalism as compared to Hispanic females and Anglo females. In the only area in which they showed significant differences by ethnicity, Anglo female higher-level administrators indicated that they were denied access to power groups as compared to Hispanic female administrators. The various perceived effects of barriers felt by the three groups gives great insight as to what each feels as the greatest hindrance to their career advancement. Once again, regardless of the type of perceived barrier effect, they each can be minimized with support, sharing, and guidance among African American, Anglo, and Hispanic female administrators.

Hispanic female administrators proved to be more successful in utilizing the strategies to overcome career barriers. They showed significant differences by ethnicity with the following strategies: seeking advanced training, being assertive in pursuing career goals, becoming professionally visible, and improving the professional image. This is important for African American and Anglo itmale administrators to take note of. However, an absent strategy from those previously referred to as being successful by Hispanic female administrators is that which involves forming a "New Girl Network." 


\section{$\underline{\text { Recommendations for Strategies of Change }}$}

This research study provided available information on the major barriers to career advancement facing African American, Anglo, and Hispanic higher-level female administrators in the Miami-Dade County Public School System. The results of the study added to the accumulating body of research on female administrators and the factors that create barriers to their full participation in educational administration. The barriers identified as significant in this study provide strong evidence of the persistence of discriminatory practices that limit the representation of female leaders of particular ethnic groups.

To assist in the elimination of barriers, it is imperative that African American, Anglo, and Hispanic female administrators network with one another and share the strengths they each possess. These women must take the initiative in counteracting the stereotypic attitudes regarding their roles in educational administration. An important advancement in that direction is the formulation of "New Girl Networks." The male administrators have mastered the informal nerwork and actively practice its advantageous strategies. A female administrator wrote the following in the voluntary narrative portion of the questionnaire. "The barrier presenting the most obstacles to me has been the "boys club" mentality of upper administrators. Only the chosen "guys" get the jobs, and the top jobs go by direct appointment... not the interview process." Women have yet to participate 
in the beneficial tactics employed by male administrators. As another female administrator wrote in the questionnaire, "Women do not necessarily support other women. Men are more supportive of other men." Yet another female administrator stated, "Females are sometimes their own worst enemies. In their quest for success, they are not willing to share their knowledge. In addition, rather than admit that they don't know a policy or procedure, they become defensive and aggressive toward other females." Yet another female administrator summed up the barriers faced by women administrators by writing, "Often, women are more of a barrier to other women getting advancement." Female administrators must realize that only through a collective, cohesive effort will the plight of females vying for top administrative positions in the school system improve.

It is also recommended that school boards and districts investigate the extent to which women of various ethnic backgrounds are represented in the upper-administrative staff and closely examine their hiring/promotion practices and procedures in order to achieve equity. Women are well represented among elementary school principals. An effort must be made to equalize their representation in the senior high principalships and superintendencies (region, associate, assistant, and deputy).

It is also recommended that female administrators strive to achieve and mantain a balanced life (professional and personal). A balanced personal life is 
defined as that which is meaningful outside the employment arena (i.e. volunteerism, sororities, friends, and an active social life). A greater percentage of the Hispanic female administrators reported being married and having the most number of children still living at home. They also reported the strategies to overcome barriers to career advancement as highly successful more often than African American and Anglo female administrators. In addition, a greater number of the Hispanic female administrators rated themselves professionally as highly successful. Acquiring the ability to focus equally, or to a greater extent. on the personal life may assist female administrators in successfully utilizing strategies to overcome barriers.

Of the 156 higher level female administrators who responded to the questionnaire, only $12(8 \%)$ had doctorate degrees. In order to be competitive with males, more females must obtain higher educational degrees Education beyond the masters and specialist levels could assist female administrators in obtaining the knowledge and skills necessary to overcome many of the barriers they perceive in hindering their career advancement.

Even if African American, Anglo, and Hispanic female administrators network with one another, strive to achieve and maintain a balanced life and obtain adva:aced degrees, it would not be sufficient. In order to achieve true equity in the hiring and promotional practices of school districts around the country: 
major changes must be made in the thought patterns of those who maintain the power in school systems: the Anglo male.

\section{$\underline{\text { Recommendations for Future Research }}$}

To further understand the factors that limit the femaie's mobility and growth in the public school system, future rescarch should focus on the political factors that limit the advancement of females to higher-administrative positions. As one female administrator wrote on the questionnaire, "Politics in the educational arena needs to be addressed as it relates to barriers to career advancement for women." Yet another female administrator concurred, "Politics at the district level is the biggest hurdle we face!" Studies in this area can lead to the understanding of the political system so that it may be eliminated.

It is also suggested that this study is replicated at the national level. .The dynamics of the Miami-Dade County School system may or may not correlate with those of other school systems around the country. Also, the large Hispanic population in Miami-Dade County does not reflect the ethnic make-up of many areas of the country. In order for this study to be generalized, it must reflect the ethnicity in a majority of the school systems around the country.

To address the concerns cited earlier by the Anglo higher-level female administrators concerning the discrimination they felt in obtaining promotions. 
future research should also focus on the rate at which various ethnic groups (Anglo, Hispanic, African American, Asian, Multiracial) are excluded or included in the hiring and promotional practices of the upper administrative ranks.

Lastly, further research should be conducted on the correlation of having a family living at home and the perception of career success. It is of interest if those higher level female administrators who are married with children feel more successful and accomplished as compared to those who are divorced or single without a family at home. 


\section{REFERENCES}

Albino, J. E. (1992). Women as leaders: The dirty word they must learn. Education Digest, 59, $33-36$.

Allen, K. \& Others (1995). African American women in educational administration: The importance of mentors and sponsors. Journal of Negro Education, 64(4), $409-422$.

$\underline{21} .(4)$

Altenbaugh, R. J. (1987). Teachers and the Workplace. Urban Education.

American Association of School Administrators (1990). Women and minorities in school administration: Facts and figures 1989-1990. Arlington, VA: AASA.

Bagenstos, N. T. (1987). Minorities and women in educational administration. Southeastern Educational Improvement Lab, 1-17.

Bell, C. S. \& Chase, S. E. (1994). The underrepresentation of women in school leadership. In Politics of Education Association Yearbook; P. Zodhiates \& C. Marshall, (Eds), The New Politics of Race and Gender. Washington DC: Falmer Press.

Berman, B. T. (1996). A pilot study for validating a questionnaire on perceptions of barriers to upward mobility by women administrators in international schools in Mexico and the United States. Tuscaloosa, AL: The MidSouth Educational Research Association. (ERIC Document Reproduction Service No. ED 406414 )

Berman, B. T. (1997). Barriers to upward mobility in international schools for women administrators. Dissertation Abstracts International, 59 (01A). (University Microfilms No. AAG98-21523).

Betz, N. E. \& Fitzgrald, L. F. (1987). The career psychology of women. San Diego: Academic Press. 
Blum, D. E. (1990). 165 Female college presidents honor progress, connect with each other, and commiserate. The Chronicle of Higher Education, A13-A 15.

Bowman, M. E. (1987). Characteristics of the women secondary school principals in California. (Doctoral dissertation, University of Southern California, 1987). Dissertation Abstracts International, 48, 3014A.

Braun, B. (1995). Women in power: Lessons in leadership development. In B. Irby \& G. Brown (Eds), Women as school executives: Voices and visions (pp. 60-63). Austin, TX: Texas Council of Women School Executives.

Brown, G., \& Irby, B. J. (1995). The perception of today's educational leaders: inclusivity of women. San Francisco, CA: Annual Meeting of the American Educational Research Association. (ERIC Document Reproduction Service No. ED 384 104).

Brown, G. \& Merchant, J. (1993). Women in leadership: A support system for surcess. In B. Irby \& G. Brown (Eds.) Women as school executives: A powerful paradigm. Huntsville, TX: Texas Concil of Women School Executives. Huntsville, TX.

Brunner, C. C. (1993). By power defined: Women in the Superintendency. A dissertation at the University of Kansas.

Burgos-Sasscer, R. (1990). The changing face of leadership: The role of Hispanics. San Francisco, CA: The Annual International Conference on Leadership Development of the League for Innovation in the Community Coliege, "Leadership 2000." (ERIC Document Reproduction No. ED 324 4077).

Campbell, M. V. (1984). A study of perceived barriers and strategies to career advancement for selected female school administrators in Indiana. Dissertation Abstracts International, 46 (02A), University Microfilms No. A.AG85-07843.

Carr, C. S.. (1995). Mexican American female principals - - In pursuit of Democratic praxis and a legacy of caring. Salt Lake City, UT: University Council for Educational Administration. (ERIC Document Reproduction Service NO. ED $396368)$. 
Carter, D. \& Wilson, R. (1990). Minorities in higher education. Ninth Annual Status Report, American Council on Education.

Clemens, J. (1990). The influence of mentors on career development of women in educational administration in Leon County, FL. Dissertation Abstracts International. 51, 353A.

Coursen, D. (1989). Two special cases: women and Blacks. Oregon. (ERIC Document Reproduction Service No. ED 309 508).

Crutcher, A. B. (1992). Female principals' perceptions of barriers that affect the upward mobility of women administrators in Alabama public education. Doctoral dissertation, The University of Alabama.

Dumas, R. G. (1979). Dilemmas of Black females in leadership. Journal of Personality and Social Systems. 2.(1).

Edson, S. K. (1981). "If they can. I can." Questioning the stereotype of the nom-aspiring woman in administration. Los Angeles. CA: The Annual Meeting of the American Educational Research Association. (ERIC Document Reproduction Service No. ED 201 069).

Edson, S. K. (1988). Pushing the limits: The female administrative aspirant. Albany, NY: State University of N.Y. Press.

Education Vital Signs: Leadership. (1993). Executive Educator December, 1993.

Elgin, J. M. (1987). A study of the career paths of women principals in the elementary schools of Tennessee. Dissertation Abstracts International, 47, 3017A.

Executive Educator. (1989). Profiles of admınistrators, 11,A7.

Erwin. B.F. \& Harmless, K. W. (1995). Women in leadership...the future edge. In B. J. Irby \& G. Brown (Eds), Women as school executives: Voices and visions (pp. 90 - 92). Austin, TX : Texas Council of Women School Executives.

Feistritzer, C. E. (1988). Profile of teachers in the U.S - 1990.

Washington, DC: national Center for Educational Information. 
Funk, C. (1986). The female executive in school administration: profiles, pluses, and problems. Arlington, TX: Annual Conference on Women and Work. (ERIC Document Reproduction Service No. ED 285 282)

Gay, L. R. (1996). Educational research competencies for analysis and application $\left(5^{\text {th }}\right.$ ed.). Englewood Cliffs NJ: Prentice-Hall.

Gill, W. E., \& Showell, D. R. (1991). The Cinderella concept of the Black female in higher education. Maryland. (ERIC Document Reproduction Service No. ED 331 379).

Ginn, L. W. (1989). A quick look at the past, present, and future of women in public school administration. Greensboro, NC: Women in Educational Administration of the North Carolina Department of Public Instruction. (ERIC Document Reproduction Service No. ED 310 498)

Gorena, M. (1996). Hispanic women in higher education administration: Factors that positively influence or hinder advancement to leadership positions. New York, NY: The Annual Meeting of the American Educational Research Association. (ERIC Document Reproduction Service No. ED 396 643).

Greyvenstein, L. A., van der Westhuizen, P. C. (1991). The untapped human resource: An holistic approach to women in educational administration. Chicago, IL: Annual Meeting of the American Educational Research Association. (ERIC Document Reproduction Service No. ED 333 577).

Gupton, S. L. \& Skick, G. A. (1995). Women leaders: Who are they and how do they compare? In B. Irby \& G. Brown (Eds.), Women as school executives: Voices and visions (pp. 6-14). Austin, TX: Texas Council of Women School Executives.

Hawkins, S. B. (1993). Sandra Rose is fighting back with education. Black Issues In Higher Education, 10(1), 12 - 14.

Hodgkinson, H. (1991). Reform versus reality. Phi Delta Kappan.73(1), 816.

Howard-Vital, M. R. \& Morgan, R. (1993). African American women and mentoring. (ERIC Document Reproduction Service No. ED 360425 ). 
Johnson, J. R. (1991). Networking: How to permeate the glass ceilingsome highlights from recent studies of networking among women. Paper presented at the Annual meeting of the American Education Research Association, Chicago, IL.

Jones, A. \& Montenegro, B. (1982). Climbing the career ladder: A research study of women in school administration. Arlington, VA: American Association of School Administrators.

Kaplan, G. (1989). Who runs our schools? Washington DS: Institute for Educational Leadership.

Kalvelage, J., Schmuck, P. \& Arends, J. (1978). Reductions in force and affirmative action: A reconcilable dilemma. Educational Economics.

Knox, A. (1991). Upward-mobility facade. The Phnenix Gazette.C1,C4.

Marshall, C. (1984). The crisis in excellence and equity. Educational Horizons. Fall, 1984.

Marshall, C. (1992). School administrators' values: A focus on atypicals. Educational Administration Quarterly, 28.(3).

Marshall, C. \& Mitchell, B. A. (1989). Women's careers as a critique of the administrative culture. Paper presented at the annual meeting of the America Educational Research Association, San Francisco, CA.

Miami-Dade County Public Schools. (1998). Statistical Abstract, 1997 1998. Miami, Florida: Office of Educational Evaluation and Management Analysis.

Moore, K. M. (1984): Careers in college and university administration: how are women affected? In A. Tringsley, C. Secor \& S. Kaplan (Eds), Women in Higher Education Administration, New Directors for Higher Education. San Francisco: Jossey-Bass, Inc.

Morie, E. D., \& Wilson, B. E. (1996). Women superintendents: New role models in leadership for change. New Orleans, LA: The Annual Conference of the Association for Supervision and Curriculum Development. (ERIC Document Reproduction Service No. ED 401 612). 
Morrison, A. M. \& Glinow, M. A. (1990). Women and minorities in management. American Psychologist, 45, 2---298.

Natale, J. (1992). Up the career ladder. The Executive Educator, 14,(2), $16-23$.

National Association of Secondary School Principals. (1988). High school leaders and their schools. Reston, VA: Author.

National Center for Education Statistics. (1994). Public and private school principals: Are there too few women? U. S. Department of Education Office of Educational Research and Improvement.

Omelas, J. P. (1991). Factors in upward mobility of Anglo and Hispanic women in Public school administration. Dissertation Abstracts International, 52(08A). (University Microfilms No. AAG92 03099).

Ortiz, F. I. (1982). Career patterns in education: women, men and minorities in public school administration. New York, NY: Praeger.

Ortiz, F. I. (1982). The distribution of Mexican American women in school Organizations. Hispanic Journal of Behavioral Sciences, 4(2), 181 - 198.

Ortiz, F. I. \& Marshall, C. (1987). The issue of gender in educational enterprise. Feminist Teacher, 2, 18-25.

Padilla, A. M. (1995). Introduction to Hispanic psychology. Hispanic Psychology: Critical Issues in Theory and Research, xi-xxi. Thousand Oaks, CA: SAGE Publications, Inc.

Patterson, J. A. (1994). Shattering the glass ceiling: Women in school administration. Chapel Hill, NC: Women's Studies Graduate Symposium. (ERIC Document Reproduction Service No. ED 383 098)

Rance, J. C. (1992). Career aspirations of Black assistant principals in public high schools. Dissertation Abstracts International, 53(02A). (University Microfilms No. AAG92-18706). 
Restine, L. N. (1993). Women in administration: Facilitators for change. Newbury Park, CA: Corwin Press, Inc. (ERIC Document Reproduction Service No. ED 358 565).

Reyes, P., \& Valencia, R. R. (1995). Educational policy and the growing Latino student population: Problems and prospects. Hispanic Psychology: Critical Issues in Theory and Research, $303-305$. Thousand Oaks, CA: SAGE Publications, Inc.

Scandura, T. A. (1990). Breaking the glass ceiling in the 1990's Research project funded by the US Dept. of Labor, Wornen's Bureau.

Schneider, A. M. (1991). Mentoring women and minorities into positions of educational leadership: gender differences and implications for mentoring: Paper presented at the Annual Conference of the National Council on Inservice Education, Houston, TX.

Schuster, D. J. \& Foote, R. H. (1990). Differences abound between male and female superintendents. The School Administrator,47(2), 14-16,18.

Shakeshaft, C. (1987). Women in educational administration. Newbury Park. CA: Sage.

Shakeshaft, C. (1989). Women in educational administration: A descriptive analysis of dissertation research and future research. In P. A. Schmuck, W. W. Charters \& R. O. Carlson (Eds.), Women in educational administration. London: Sage Publications.

Sulowski, S. S. (1988). A descriptive profile of female line administrators in Vew York State. Dissertation Abstracts International,48, 117A.

Truesdale, U. P. (1988). Employment practice and procedures which result in high percentages of women in secondary school principalships. (Doctoral dissertation, University of South Carolina, 1988). Dissertation Abstracts International,49. 2889-A.

Waddell. A. (1994). Women in school administration: Where are they? The Delta Kappa Gamma Bulletin, 60.(2), 20 - 25. 
Warren, P. B. (1990). Massachusetts female public school administrators and their professional development. (Doctoral dissertation. Boston University, 1990). Dissertation Abstracts International, 51, 51A.

W'ebber, M. B., Feldman, J. R. \& Poling, E. C. (1981). Why women are underrepresented in educational administration. Educational Leadership, 38, (4).

Wesson, L. H. (1995). Equity issues for women and mmorities in educational administration. In B. Irby \& G. Brown (Eds.), Women as school executives: Voices and visions (pp. $149-157$ ). Austin, TX: Texas Council of Women School Executives.

Whitaker, K. S. \& Lane, K. (1990). Is a woman's place in administration? The School Administrator, 47,8-12.

W'oo, L. C. (1985). Women administrators: Profiles of success. Phi Delta Kappan. 67. 2-89. 
Appendix A

\section{MIAMI-DADE COUNTY PUBLIC SCHOOLS}

EDUCATIONAL EVALUATION \& MANAGEMENT ANALYSIS • 1500 BISCAYNE BOULEVARD, SUITE $225 \bullet$ MIAMI, FLORIDA 33132

Roger C. Cuevas

Superintendent of Schools

Robert A. Collins

Executive Director

Educational Evaluation and Management Analysis

(305) 995-7529

FAX: 995-7571

\author{
Dade County School Board \\ Dr Solomon C Stinson. Chair \\ Mr. Demetrıo Pérez, Jr. Vice-Chair \\ Mr. G Holmes Braddock \\ Mr Renier Diaz de la Pontilla \\ Ms Peria Tabares Hantmar \\ Ms. Betsy H Kaplan \\ Dr. Michael M Krop \\ Mrs Manty Sabates Morse \\ Ms. Frederica $S$ Wilson
}

August 14, 1998

Ms. Marie Byrd

555 N.W. 210 Street \#203

Miami, Florida 33169

Dear Ms. Byrd:

I am pleased to inform you that the Research Review Committee of the Miami-Dade County Public Schools (MDCPS) has approved your request to conduct the study, "A Study of the Differences between African-American, Hispanic, and Anglo Women on the Perceived Barriers and Strategies to Career Advancement in Public School Administration." The approval is granted with the following conditions:

1. The participation of all subjects is voluntary.

2. The anonymity and confidentiality of all subjects must be assured.

3. The study will involve approximately 400 MDCPS administrators.

4. The MDCPS internal school mail system cannot be used in conducting the study.

It should be emphasized that the approval of the Research Review Committee does not constitute an endorsement of the study. It is simply a permission to request the voluntary cooperation in the study of individuals associated with the MDCPS. It is your responsibility to ensure that appropriate procedures are followed in requesting an individual's cooperation, and that all aspects of the study are conducted in a professional manner. With regard to the latter, make certain that all documents and instruments distributed within the MDCPS as a part of the study are carefully edited.

The computer-generated data for the study will be provided by Ms. Gisela Feild of the Office of Educational Planning of the MDCPS. Contact her at (305) 995.7511 to arrange a meeting to review your request and determine the cost. 
The approval number for your study is 561 . This number should be used in all communications to clearly identify the study as approved by the Research Review Committee. The approval expires on April 30, 1999. During the approval period, the study must adhere to the design, procedures and instruments which were submitted to the Research Review Committee. If there are any changes in the study as it relates to the MDCPS, it may be necessary to resubmit your request to the committee. Failure to notify me of such a change may result in the cancellation of the approval.

If you have any questions, please call me at (305) 995.7501. Finally, remember to forward an abstract of the study when it is complete. On behalf of the Research Review Committee, I want to wish you every success with your study.

Sincerely,

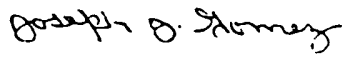

Joseph J. Gomez, Ph.D.

Chairperson

Research Review Committee

JJG:cg

cc: Ms. Gisela Feild 


\section{Florida International University \\ University Park Campus \\ Department of Educational Leadership and Policy Studies \\ Miami, Florida 33199}

October 21, 1998

Dear Fellow Administrator:

You are one of approximately 260 females who serve in a top educational administrative position in Miami-Dade County Public Schools. You have been selected to participate in a research study on the barriers and strategies to career advancement for women in educational administration.

This study is specifically designed to solicit your perceptions of the barriers you may have encountered in your career advancement as an administrator, the effects of these barriers, and the strategies you have used to successfully overcome these barriers. The results of this study will serve as a resource and will provide a source of information for planning future strategies and programs to counteract obstacles faced by females of various races.

Your response will be completely confidential. Therefore, please take a few moments to respond. Your participation in completing this survey is essential to the success of the study.

If there are any questions, please contact me at (305) 624 - 9648.

Thank you in advance for your cooperation and time.

Sincerely,

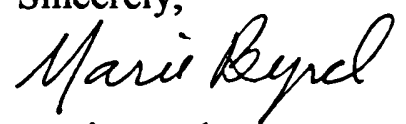

Marie Byrd

Doctoral Candidate, Assistant Principal

Enclosure 
November 19, 1998

Dear Female Administrator:

Your assistance is needed! Recently you received a MDCPS approved (approval \#561) survey designed to gather useful information on the barriers and strategies to career advancement for women in higher-level administrative positions. I am now concluding the data collection phase of this research study and have not yet received your completed questionnaire. I am certain you have been very busy and have perhaps forgotten about the questionnaire. If this is the case, please take a few moments from your hectic schedule and join the other female administrators who have supported this important effort by returning the questionnaire in the previously mailed self-addressed stamped envelope as soon as possible.

If you have returned the survey, please discard this notice. Otherwise, your cooperation and time will be greatly appreciated.

Please feel free to contact me at (305) $624-9648$ if there are any questions or if you would like an additional survey. I look forward to receiving your completed survey.

Sincerely,

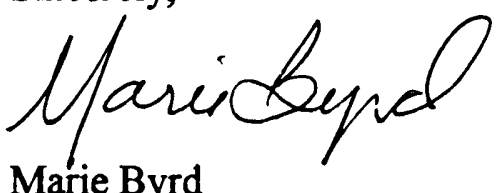

Marie Byrd

Doctoral Candidate

Assistant Principal 


\section{Directions:}

Your responses on this survey are completely anonymous. The survey is coded to facilitate follow-up inquiries. In reporting the results, only the statistical summaries of the responses will be given. Extreme care will be taken to ensure the confidentiality of the respondents.

Please attempt to answer each question on the survey.

Thank you for your cooperation and assistance in this important study.

Code \#

I. Personal Characteristics

1. What is your age?
a. Under 30
b. $30-34$
d. $40-44$
g.
e. $-45-49$
h. $55-59$
c. $35-39$
i. $60-64$ 65 or older

2. With what ethnic group would you identify yourself?
a. White (non Hispanic)
b. Black (non Hispanic)
c. Hispanic
d. Asian, Pacific Islander
e. Multiracial
f. —other, Please Specify:

3. Where were you born?

4. What is your current marital status?
a. Single
c. Widowed
e. _L Separated
b. $\longrightarrow$ Married
d. Divorced
f. Other, Please Specify: 
5. How many children do you have who are living at home?

II. Professional Characteristics

6. What is the highest degree you hold?
a. Bachelors
b. Masters
c. Specialist
d. Doctorate

7. What is the title of your present position?
a.
b. Elementary School Principal
c.
d. Middle School Principal
e.
f.
g.
h.
i. Senior High Principal Director Region Superintendent Associate Superintendent
Assistant Superintendent
Deputy Superintendent
__ Other, Please Specify:

8. How many years of teaching experience did you have prior to obtaining your present position?

9. At what age were you appointed to your present position?
a. Under 30
d. $40-44$
g.
h. $55-59$
b. $-30-34$
e. $45-49$ $60-64$
c. $35-39$
f. $50-54$
i. 65 or older

10. Counting the present year, how many years have you been employed in your present position?

11. Do you consider your present position to be your ultimate occupational goal? If not, to what position do you ultimately aspire? 
12. At present, how do you rate yourself professionally?
a.
b. Moderately successful
c. Unsuccessful

Please explain:

\section{Barriers to Career Advancement}

On the scales below, please circle the number which best approximates your perception of the degree to which the listed factors have been a barrier to you in pursuing your career goals as an administrator. Please circle only one number for each factor.

13. Lack of a professional network (i.e., a support group to develop strategies for career advancement, to address specific problems, to share experiences)

\begin{tabular}{ccccccc}
1 & 2 & 3 & 4 & 5 & 6 & 7 \\
\hline Not a Factor & & & & & Serious Factor
\end{tabular}

14. Teachers, parents, and community preferences for male rather than female administrators

\begin{tabular}{ccccccc}
1 & 2 & 3 & 4 & 5 & 6 & 7 \\
\hline Not a Factor & & & & & Serious Factor
\end{tabular}

15. Lack of prior opportunities to qualify for higher level administrative positions

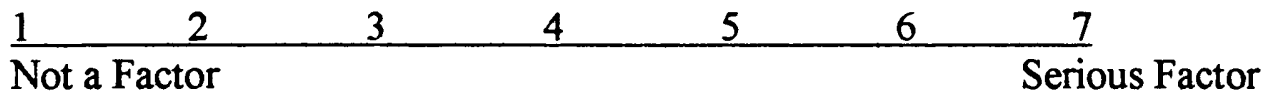

16. Differential treatment on the basis of sex during the formal application, screening, and selection processes.

\begin{tabular}{ccccccc}
1 & 2 & 3 & 4 & 5 & 6 & 7 \\
\hline Not a Factor & & & & & Serious Factor
\end{tabular}


17. Existence of "cronyism" or the "buddy system" where men refer their male associates to jobs

\begin{tabular}{ccccccc}
1 & 2 & 3 & 4 & 5 & 6 & 7 \\
\hline Not a Factor & & & & & Serious Factor
\end{tabular}

18. Lack of career mobility (i.e., more place-bound)

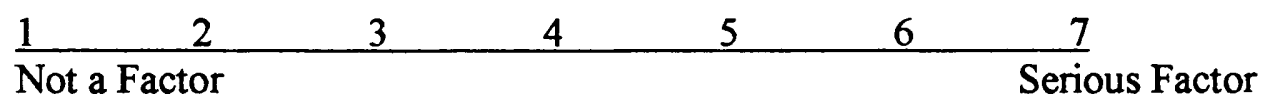

19. Conflicts between the roles of wife/mother and career woman

\begin{tabular}{lcccccc}
1 & 2 & 3 & 4 & 5 & 6 & 7 \\
\hline Not a Factor & & & & & Serious Factor
\end{tabular}

20. Lack of role models

\begin{tabular}{ccccccc}
1 & 2 & 3 & 4 & 5 & 6 & 7 \\
\hline Not a Factor & & & & & Serious Factor
\end{tabular}

21. Problems in overcoming stereotypic attitudes about women's appropriate roles in society

\begin{tabular}{lcccccc}
1 & 2 & 3 & 4 & 5 & 6 & 7 \\
\hline Not a Factor & & & & & Serious Factor
\end{tabular}

22. Lowered aspirations because of limited opportunities for growth and advancement

\begin{tabular}{ccccccc}
1 & 2 & 3 & 4 & 5 & 6 & 7 \\
\hline Not a Factor & & & & & Serious Factor
\end{tabular}


23. Superior's negative attitudes about women's competency and effectiveness in administrative positions

\begin{tabular}{lllllll}
1 & 2 & 3 & 4 & 5 & 6 & 7 \\
\hline
\end{tabular}

Not a Factor

Serious Factor

24. Lack of encouragement or support from family and peers

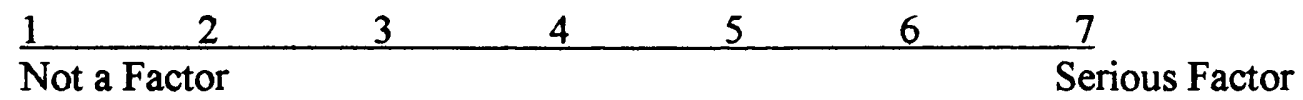

25. Exclusion from the informal socialization process into the profession (i.e., the "Good Old Boy Network")

\begin{tabular}{lcccccc}
1 & 2 & 3 & 4 & 5 & 6 & 7 \\
\hline Not a Factor & & & & & & Serious Factor
\end{tabular}

26. Lack of influential mentors

\begin{tabular}{ccccccc}
1 & 2 & 3 & 4 & 5 & 6 & 7 \\
\hline Not a Factor & & & & & Serious Factor
\end{tabular}

27. Small proportion of women in higher-level administration which affects how you are perceived by and responded to by colleagues (e.g., as "tokens")

\begin{tabular}{ccccccc}
1 & 2 & 3 & 4 & 5 & 6 & 7 \\
\hline Not a Factor & & & & & Serious Factor
\end{tabular}

28. Lack of motivation to pursue particular administrative positions because of past obstacles encountered

\begin{tabular}{lllllll}
1 & 2 & 3 & 4 & 5 & 6 & 7 \\
\hline Not a Factor & & & & & Serious Factor
\end{tabular}


29. Higher level of training required in order to be competitive with male colleagues

\begin{tabular}{lllllll}
1 & 2 & 3 & 4 & 5 & 6 & 7 \\
\hline
\end{tabular}

Not a Factor

Serious Factor

IV. Please give your perceptions of how each perceived barrier has affected your career advancement by circling the appropriate number on the scale.

\begin{tabular}{ccccc}
1 & 2 & 3 & 4 & 5 \\
$\begin{array}{c}\text { Not at } \\
\text { All }\end{array}$ & $\begin{array}{c}\text { To Some } \\
\text { Ertent }\end{array}$ & $\begin{array}{c}\text { To a } \\
\text { Moderate } \\
\text { Extent }\end{array}$ & $\begin{array}{l}\text { To a } \\
\text { Large } \\
\text { Extent }\end{array}$ & $\begin{array}{c}\text { To a } \\
\text { Great } \\
\text { Extent }\end{array}$ \\
\hline
\end{tabular}

30. Career was delayed due to family responsibilities

12

3

4

5

31. Denied access to power groups that make important decisions

1

2

3

4

5

32. Aspirations and motivation thwarted because of difficulty encountered in advancing

1

2

3

4

5

33. Interruption of career

12

3

4

5

34. Having to accept less attractive and less challenging jobs

12

3

4

5

35. Applied less frequently for available administrative positions because of obstacles encountered

12

3

4

5

36. Exclusion from informal network 1

2

3

4

5

37. Promotion into dead-end positions which are not commensurate with abilities and experience 
38. Problems with finding a balance between feminine identity and professionalism

39. Limited opportunities to advance professionally due to gender. bias

1

2

3

4

5

V. Please check the column which best represents your perception of the success rate of each listed strategy in accomplishing career goals. Check Never Used if you have never used this particular strategy.

1

Unsuccessful

Successful
2 Somewhat Successful

41. Setting career goals and formulating a plan of action

42. Developing/utilizing "New Girl Network"

42. Enlisting influential sponsors

43. Seeking advanced training and certification

44. Being more assertive in pursuing career goals

45. Becoming professionally visible

46. Improving professional image 
47. Attending seminars and administrative training workshops to improve professional and interpersonal skills

48. Learning to cope with multiple roles - wife/ mother/professional

49. Obtaining support from family and/or peers

Please utilize the space below for any additional comments on either the perceived barriers, the effects of the barriers, and/or the strategies utilized to ... overcome the barriers as a female administrator in the public school system.

Thank you for your time and effort in completing this survey! If you are interested in the results of this research study, please print your name and address below.

Name:

Mailing Address: 


\section{ADMINISTRATIVE STAFF}

ADMINISTRATIVE STAFF INCLUDE PERSONNEL WHO PERFORM MANAGEMENT ACTIVITIES, SUCH AS DEVELOPING BROAD POLICIES FOR THE SCHOOL DISTRICT AND EXECUTING THOSE POLICIES THROUGH THE DIRECTION OF PERSONNEL AT ALL LEVELS WITHIN THE DISTRICT. ADMINISTRATIVE PERSONNEL ARE GENERALLY HIGH-LEVEL RESPONSIBLE PERSONNEL WHO HAVE BEEN ASSIGNED THE RESPONSIBILITIES OF SYSTEM-WIDE OR SCHOOL-WIDE FUNCTIONS, SUCH AS SUPERINTENDENTS, DEPUTY SUPERINTENDENTS, ASSOCIATE SUPERINTENDENTS, ASSISTANT SUPERINTENDENTS, PRINCIPALS, ASSISTANT PRINCIPALS, VOCATIONAL CENTER DIRECTORS, AND OTHERS WHO PERFORM MANAGEMENT ACTIVITIES.

\section{PROFESSIONAL AND TECHNICAL SUPPORT STAFF}

SUPPORT STAFF INCLUDE PERSONNEL WHO FUNCTION IN A SUPPORT CAPACITY PERFORMING WORK ASSOCIATED WITH RECOGNIZED PROFESSIONAL/TECHNICAL FIELDS. SUPPORT STAFF ARE USUALLY REQUIRED TO HAVE A COLLEGE DEGREE, AND/OR POSTCOLLEGE EDUCATION/TRAINING, BACCALAUREATE DEGREE, OR THE ATTAINMENT OF TECHNICAL KNOWLEDGE AND SKILLS THROUGH POST-SECONDARY OR VOCATIONAL STUDY AND/OR EXTENSIVE WORK EXPERIENCE IN A SPECIFIC FIELD. 


\section{ADMINISTRATIVE STAFF}

JOB

CODE JOB TITLE

OFFICIALS, ADMINISTRATORS, MANAGERIAL: INSTRUCTIONAL(02, 03, 08)

02 Deputy, Associate, Region, Assistant Superintendent

0025 Deputy Superintendent, School Operations $\quad 54$

0220 Deputy Superintendent for Education $\quad 54$

0300 Region Superintendent 52

0684 Associate Superintendent, Elementary and Secondary Education 52

0203 Assistant Superintendent, Alternative Education and Dropout 50

0267 Assistant Superintendent, Applied Tech., Adult, and Career Educ. 50

0348 Assistant Superintendent, School Operations 50

0680 Assistant Superintendent, Pro. Dev. \& Career Advancement 50

0683 Assistant Superintendent, Educational Services 50

\section{Director}

0120 Senior Executive Director, Media Programs

48

0139 Senior Executive Director, Management Training 48

0212 Region Director, ESE/Federal Programs 48

0240 District Director, Fundamental Skills 48

0304 Region Director, Adult Education 48

0305 Region Director - Instructional 48

0306 Region Director, School Operations 48

0308 District Director, School Operations 48

0309 District Director, Instruction 48

0313 District Director, Instructional Support 48

0314 District Director, Educational Planning 48

0404 District Director, Life Skills 48

0460 District Director, Title I 48

0580 District Director, Alternative Education 48

0662 District Director, Schools of Choice 48

0138 Executive Director, Dropout Prevention 47

0253 Executive Director, Bilingual/Foreign Language 47

0273 Executive Director, Title I Programs 47

0362 Executive Director, Advanced Academic Program 47

0598 Executive Director, Media Programs 47

0867 Executive Director, USI Quality Assessment 47

0180 Director II, Career Education $\quad 46$

0244 Director II, General Education 46

0269 Director II, Vocational/Business Services 46

0368 Director II, Bilingual Training 46

0652 Director II, ESE Programs 46

0166 District Supervisor, Early Childhood Programs 45

0223 Director I, School To Work 45

0286 Director I, Community Outreach 45 


\section{ADMINISTRATIVE STAFF}

JOB

CODE JOB TITLE

GRADE

0349 Director I, School Operations

0504 Director I, Migrant Education 45

0587 Director I, Management Training 445

0868 Director I, USI $\quad 45$

0869. Director I, Urban Systemic Initiative 45

08 Supervisor, Coordinator, Consultants.

0116 Instructional Supervisor, Parent Education 45

0181 Instructional Supervisor, Business Education 45

0192 Instructional Supervisor, Adult/Community Education 45

0193 Instructional Supervisor, GMAC $\quad 45$

0208 Instructional Supervisor, Exceptional Student Education 45

0225 Instructional Supervisor, Health/Public Service Education 45

0227 Instructional Supervisor, Home and Family Education 45

0229 Instructional Supervisor, Industrial Education 45

0231 Instructional Supervisor, Industrial Arts 45

0241 Instructional Supervisor, Language Arts $\quad 45$

0243 Instructional Supervisor, Art Education 45

0250 Instructional Supervisor, School Library/Media Services 45

0252 Instructional Supervisor, Driver Education 45

0256 District Supervisor, Talent Program 45

0264 Instructional Supenvisor, Comprehensive Health Programs 4.5

0266 Instructional Supervisor, Science Education 45

0268 Instructional Supervisor, Substance Education 45

0271 Instructional Supervisor, Psychological Services $\quad 45$

0278 Instructional Supervisor, Reading 45

0291 Instructional Supervisor, Foreign Language Education 45

0361 Instiuctional Supervisor, Instructional Technology 45

0486 District Supervisor, Parent Outreach 45

0506 Instructional Supervisor, FDLRS 45

0510 District Supervisor, Title I 45

0550 District Supervisor, Instructional Support 45

0560 Instructional Supervisor, Pre-Kindergarten/ESE Programs 45

0210 Supervisor II, Community Education $\quad 44$

0263 Supervisor II, Bilingual Curriculum 44

0527 District Coordinator, Magnet Technology 44

0572 Supervisor II, Migrant Education 44

0559 Supervisor I, AIDS Education 43

0182 Coordinator III, P/O Therapy 42

0418 Parent Participation Coordinator 42

0259 Coordinator II, FDLRS $\quad$. F 41

0520 Coordinator I, Able/Disabled Services 40 
JOB

CODE JOB TITLE

OFFICIALS, ADMINISTRATORS, MANAGERIAL: NON-INSTRUCTIONAL $(05,06)$

05 Deputy, Associate, Assistant Superintendent

0008 Deputy Superintendent of Schools 56

0006 Deputy Superintendent, Personnel Management and Services 54

0016 Chief Financial Officer $\quad 54$

0021 Deputy Superintendent, Federal Programs and Grants Admin. 54

0022 Chief Facilities Officer $\quad 54$

0028 Deputy Superintendent, Management and Accountability 54

0159 Chief Officer $\quad$. 54

0101 Chief Auditor $\quad 52$

0366 Associate Superintendent, Information Technology 52

0371 Controller $\quad 52$

0685 Associate Superintendent, Procurement and Materials Management 52

0730 Administrator, Community Participation 52

0083 Labor Lawyer $\quad 50$

0086 Assistant Superintendent, Human Resources 50

0118 Assistant Chief of Management and Compliance Audits 50

0364 Chief Budget Officer $\quad 50$

0365 Treasurer $\quad 50$

0465 Assistant Superintendent, Facilities Operations 50

0682 Assistant Superintendent, Employee Support Programs 50

06 Director, Supervisor, Coordinator

0082 Senior Executive Director, Wage and Salary Administration 48

0126 District Director, Compliance and Investigative Audits 48

0145 District Director, Community Participation 48

0372 Assistant Controller 48

0436 Senior Executive Director, Food and Nutrition 48

0654 Assistant Chief Budget Officer 48

0668 Senior Executive Director, Risk Management 48

0687 Senior Executive Director, Personnel Administration 48

0688 Senior Executive Director, Professional Standards 48

0742 Senior Executive Director, Transportation 448

0751 District Director, Labor Relations 48

0903 Senior Executive Director, Facilities Operations 48

0033 Executive Director, Systems and Programs 47

0034 Executive Director, Budget and Operations 47

0080 Executive Director, Personnel Administration 47

0110 Executive Director, Risk Management 47

0136 Executive Director, Capital Construction Audits 47

0142 Executive Director, Management Selection 47

0151 Executive Director, Information Services 47 


\section{ADMINISTRATIVE STAFF}

JOB

PAY

CODE JOB TITLE

GRADE

0163 Executive Director, State Legislative Program 47

0173 Executive Director, Grants Administration 47

0185 Chief, School Police $\quad 47$

0287 Executive Director. Professional Standards 47

0458 Executive Director, Project Contract Management 47

0577 Executive Director, Purchasing $\quad 47$

0615 Administrator on Special Assignment . 47

0638 Executive Director, Student Transfers 47

0639 Executive Director, Architectural Support Services 47

0644 Executive Director, Network Services 47

0645 Executive Director, Facilities Compliance 47

0647 Executive Director, Capital Construction Compliance 47

0648 Executive Director, Site Planning 47

0735 Executive Director, Program Evaluation 47

0737 Administrator $\quad 47$

0750 Executive Director, Facilities Operations 47

0768 Executive Director, Materials Management 47

0079 Director II, Communication Services 46

0085 Director II, Instructional Staffing 46

0104 Director II, Professional Standards 46

0158 Director II, Certification 46

0261 Director II, Community Education $\quad$ : 46

0379 Director II, Payroll Administration 46

0416 Director II, Vehicle Maintenance 46

0478 Director II, Capital Budget Planning 46

0650 Director II, School Budgets 46

0655 Director II, District Budgets 46

0765 Director II, Grants Management 46

0877 Director II, Transportation 46

0076 Director I, Management Analysis $\quad 45$

0089 Director I, Wage and Salary Administration 45

0092 Director I, Retirement/Leave/Unemployment Compensation 45

0186 Assistant Chief of Police 45

0202 Director I, Instructional Staffing and Recruiting . 45

0217 Director 1, Alternative Education $\quad 45$

0283 Director I, Professional Orientation Program 45

0463 Director I, District Office $\quad 45$

0488 Director I, Dade Area Center for Educational Enhancement 45

0524 District Supervisor, Grants Administration 45

0610 Director I, Student Transfers 45

0775 Director I, DOE Liaison 45

0789 Director I, Development and Governmental Affairs 45

0857 Client Liaison $\quad 45$

0071 Supervisor II, Program Evaluation 44

0096 Supervisor II, Wage and Salary 44

0198 Data Security Administrator

0233 Supervisor II, Vocational Fiscal Services $\quad 44$

0516 Supervisor II, Teacher Training 44 


\section{ADMINISTRATIVE STAFF}

JOB

CODE JOB TITLE

0702 Supervisor II, Management Selection 44

0117 Supervisor I, Evaluation

0187 Supervisor I, Region Operations

0740 Supervisor I, Employee Assistance

0401 Fringe Benefits Manager 42

PRINCIPALS $(09,10,11,12)$

09 Elementary

0154 Principal, Partners in Education 47

0311 Elementary Principal $\quad 47$

0350 Interim Elementary Principal $\quad 45$

0605 Temporary Elementary Principal $\quad 45$

\section{Middle}

0316 Middle School Principal

0351 Interim Middle. Principal

0604 Temporary Middle Principal

\section{Senior High}

0321 Senior High Principal

0352 Interim Senior High Principal

0603 Temporary Senior High Principal

\section{Other Principals}

0322 Principal, Exceptional Education 47

0326 Principal, Adult Education $\quad 47$

0332 Principal, Opportunity School $\quad 47$

0336 Principal, Regional Vocational Technical Center 47

0339 Principal, Vocational Center 4.

0353 Interim Regional Vocational Technical Principal 45

0354 Interim Adult Education Principal $\quad 45$

0355 Interim Principal Opportunity School $\quad 45$

0356 Interim ESE Principal $\quad 45$

0419 Interim Principal, Cope Center 45

0617 Temporary Adult Education Principal 45

0618 Temporary Principal Regional Vocational Technical 45 
Deputy Superintendent, District Office $\quad 54$

Deputy Superintendent $\quad 54$

Deputy Superintendent, Legislative and Labor Relations $\quad 54$

Associate Superintendent, District Operations $\quad 52$

Associate Superintendent, Facilities Management $\quad 52$

Associate Superintendent, Professional Standards and Operations 52

Associate Superintendent, Human Resources Development $\quad$ - 52

Associate Superintendent for Personnel Management $\quad 52$

Associate Superintendent, Instructional Support 52

Chief of Staff $\quad 52$

$\begin{array}{ll}\text { Controller } & 50\end{array}$

Assistant Superintendent, Facilities Management $\quad 50$

Assistant Superintendent, School Based Management $\quad 50$

Assistant Superintendent, Management Selection $\quad 50$

Assistant Superintendent, Capital Improvement Projects $\quad 50$

Executive Assistant to the Superintendent $\quad 49$

Senior Executive Director, Facilities $\quad 48$

Senior Executive Director, Management Audits 48

Executive Director, Management Assessment Center 47

Executive Director, Management Systems and Control 47

Executive Director, Mathematics/Science and Computer Education : : 47

Executive Director, Life Skills $\quad 47$

Executive Director, MIS $\quad 47$

Executive Director, Language Arts and Library Media Services 47

Executive Director, Transportation $\quad 47$

Executive Director, USI $\quad 47$

Executive Director, Student Services $\quad 47$

Executive Director, Social Studies/Health $\quad 47$

Executive Director, Personnel $\quad 47$

Executive Director, Office of Superintendent $\quad 47$

Executive Director, Finance $\quad 47$

Executive Director, Bilingual Education $\quad 47$

Executive Director, Capital Projects $\quad 47$

Executive Director, Instructional Technology 44

Executive Director, Academy for Instructional Leadership $\quad 47$

$\begin{array}{ll}\text { Executive Director, Community Education } & 47\end{array}$

Executive Director, Athletics and Activities $\quad 47$

Executive Director, Instructional Training $\quad 47$

Executive Director, Grants Administration $\quad 47$

Executive Director, Exceptional Student Education 47

Executive Director, Employment Standards $\quad 47$

Executive Director, Dropout Prevention $\quad 47$

Lead Administrator Superintendent's Academy $\quad 47$

Liaison Director, National Science Foundation/Urban Systemic Initiative $\quad 47$

Director II, Department of Management Selection 46

Director II, Department Dropout Prevention 46

Director II, Community Participation 46 
Director II, ARRM 46

Director II, Department of Computer Education/Technology 46

$\begin{array}{ll}\text { Director II, Personnel Administration } & 46\end{array}$

Director II, School Athletics and Activities $\quad 46$

Director II, Subject Area Testing 46

Director II, EH/SED Programs $\quad 46$

Director II, Labor Relations $\quad 46$

Director II, Grants 46

Director II, Educational Planning $\quad 46$

Director II, Gifted Programs $\quad 46$

Grants Management Director $\quad 46$

Administrative Assistant to the Superintendent 45

$\begin{array}{ll}\text { Administrator } & 45\end{array}$

Director I, Management Training $\quad 45$

Director I, Non-Instructional Employment Standards $\quad 45$

Director I, Professionalization Information and Publication 45

Director I, Magnet Program Planning $\quad 45$

Director I, Instructional/Non-Instructional Training $\quad 45$

Director I, Technical Services $\quad 45$

Director I, SBAB/Operations Services $\quad 45$

Director I, EEOUC Opportunity $\quad$ : 445

Director I, Athletics and Activities $\quad 45$

Director I, Alternative Education $\quad 45$

Director I, Business Management Personnel $\quad 45$

Director I, Capital Planning $\quad 45$

Director I, District Office $\quad 45$

Director I, Desegregation/Support Operations 45

Instructional Supervisor, Staff Development 45

Instructional Supervisor, Gifted Education and Allied Programs 45

District Coordinator, Instructional $\quad 44$

Instructional Coordinator, GEMS

Region Instructional Coordinator $\quad 44$

Supervisor II, Contracted Programs 44

Supervisor II, Bilingual Curriculum $\quad 44$

Supervisor II. Child Advocacy $\quad 44$

Supervisor II, Teacher Training $\quad 44$

Supervisor II, Support Personnel Training $\quad 44$

Supenisor II, Vocational Adult Facilities $\quad 44$

Supervisor II, Vocational Adult Facilitator $\quad 44$

Supervisor II, Science Education 44

Supervisor II, Teacher Education Center 44

Supervisor II, Management Training . $\quad 44$

Supervisor II, Satellite Operations $\quad 44$

Supervisor II, Home/Hospital 44

Supervisor II, Language Arts Education 44

Supervisor II, Procurement Management $\quad 44$

Supervisor I, Financial Services 43 
VITA

MARIE BYRD

December 12, 1964

1986

1986-1994

1990

1990-1991

1991-1992

1994-1996

1996-Present
Born, Blountstown, Florida

B.S., Elementary Education

Florida State University

Tallahassee, Florida

Elementary School Teacher

Miami-Dade County Public Schools Miami, Florida

M.S., Elementary Education

Florida International University

Miami, Florida

Upward Bound Counselor

Miami-Dade Community College

Miami, Florida

Writing Instructor

Miami-Dade Community College

Miami, Florida

Title One Reading Curriculum Specialist Miami-Dade County Public Schools Miami, Florida

Assistant Principal

Miami-Dade County Public Schools

Miami, Florida 